UCRL-ID-127400

\title{
The effect of foundation flexibility on the vibrational stability of the National Ignition Facility optical system support structures
}

\author{
David McCallen
}

May 1997

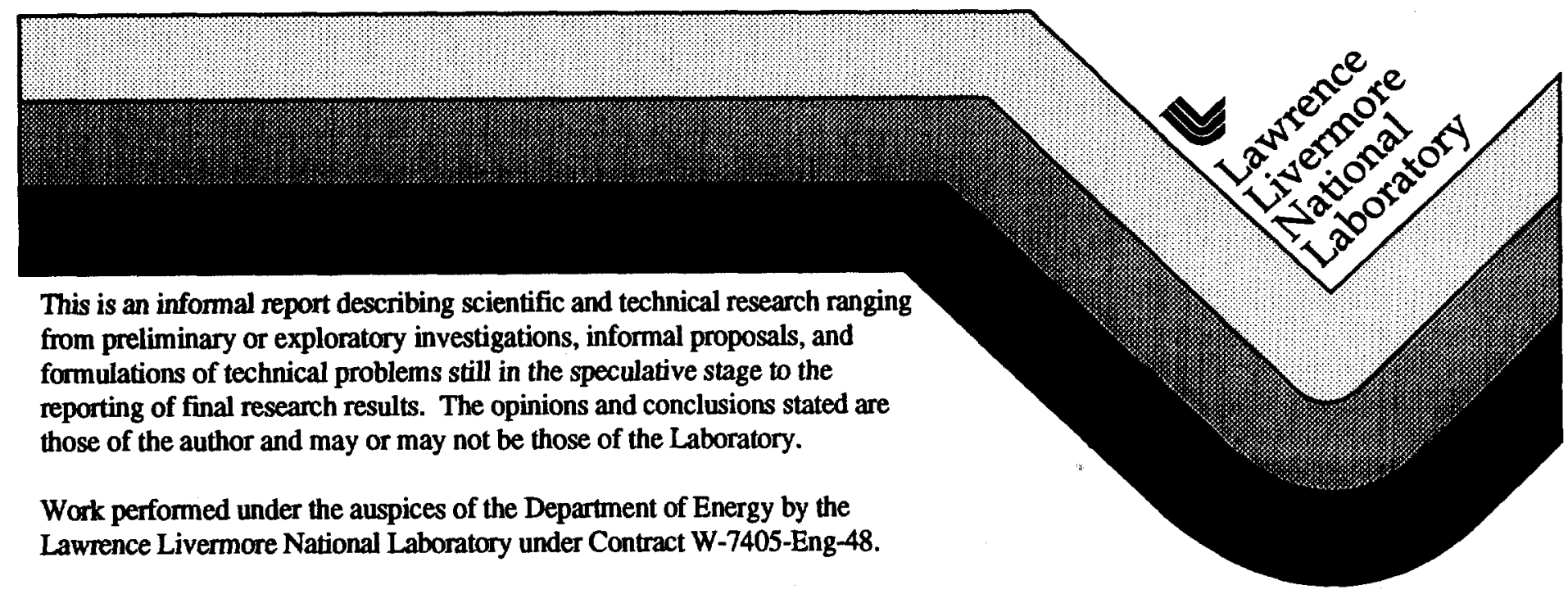


This document was prepered as an scoount of work sponsoced by an agency of the United Statea Government. Neither the United States Government not the University of California mor any of their employees, makes any warranty, express or implied, or assumes any legal liability or responsibility for the nccurncy, completeness, or usefulmess of any information, apperatus, product, or process disclomed, ar represents that its ue would aot infringe privately owned rights. Referesce herein to any specific commercial product, process, or service by tride name, trademark, manufacturer, a otherwise, does not mecesencily conatitute or imply its endorsement, recommendation, or favoring by the United States Government or the University of California. The viewa and opinions of authors expressed herein do not necessarily state or reflect those of the Unitod States Government or the University of Californie, and shall not be used for advertiaing or product endorsement purposes.

This report has been reproduced directly from the best available copy.

Available to DOE and DOE contractors from the

Office of Scientific and Technical Information

P.O. Box 62, Oak Ridge, TN 37831

Prices available from (615) 576-8401, FTS 626-8401

Available to the public from the

National Technical Information Service

U.S. Depurtment of Commerce

S285 Port Royal Rd.,

Springfield, VA 2216 . 


\section{The effect of foundation flexibility on the vibrational stability of the National Ignition Facility optical system support structures}

\section{Contents}

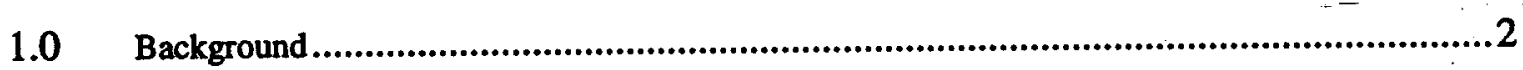



3.0 Finite element model of a structure-soil system ..................................................................

4.0 Frequency dependent scattering of propagating waves by an imbedded mat foundation ............22

5.0 Assessment of the influence of soil-structure-interaction .....................................................30

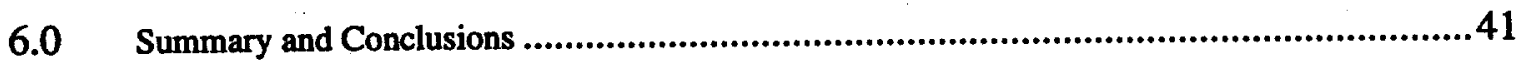

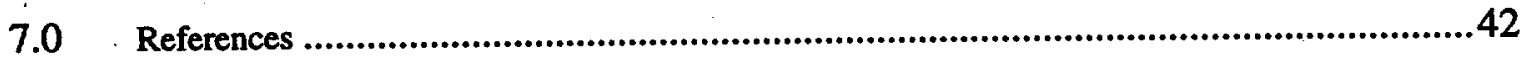




\title{
The effect of foundation flexibility on the vibrational stability of the National Ignition Facility optical system support structures
}

\author{
David McCallen \\ Structural and Applied Mechanics Group \\ New Technologies Engineering Division \\ Lawrence Livermore National Laboratory
}

\begin{abstract}
Alignment requirements for the National Ignition Facility (NIF) optical components will require a number of support structures which minimize the system displacements and deformations. The stringent design requirements for this facility will result in a system in which vibrations due to ambient environmental loads (e.g. foundation motion due to typical traffic loads, microseisms or nearby equipment) will have a significant, and perhaps predominant, influence on the design of the supporting structures. When considering the total deformations and displacements of the structural systems, the contribution of the foundation to the overall system flexibility must be addressed. Classical fixed-base structural analyses, which are predicated on an assumption of an infinitely rigid foundation system, neglect the influence of foundation flexibility and for the vibration regime in which the NIF structures reside, may result in significant underestimation of the system ambient vibration displacements.

In the work described herein, parametric studies were performed in order to understand the potential contributions of soil-structure-interaction (SSI) to optical system displacements. Time domain finite element analyses were employed to quantify the effect of wave scattering by the mat foundation and the effects of inertial SSI due to the rocking of the massive shear wall support structures. A simplified procedure is recommended for accounting for SSI effects in the design of the special equipment structures. The simplified approach consists of applying a scale factor to displacements obtained from fixed base analyses to approximately account for the effects of soil-structure interaction and variable support input motion.
\end{abstract}

\subsection{Background}

As the preliminary designs of the NIF support structures have progressed, the structural configurations have necessarily evolved to massive, stiff, high frequency (10-15 Hz ) reinforced concrete shear wall structures (see Fig. 1 for example) in order to meet stringent vibration tollerances. These massive, stiff superstructures will mitigate superstructure deformations as intended. However, the stiff structures result in a relatively high demand on the structure foundations. The more massive the superstructure, the more difficult it is to develop a true fixed base condition at the superstructure/foundation interface as shown schematically in Fig. 2. The stiffness supplied by the foundation system must be commensurate with the stiffness supplied by the superstucture in order to achieve an efficient optical support system and to fully exploit the stiffness supplied by the massive superstructures. If the foundation is too flexible the ultimate effect of massive superstructures will be to push the system deformations into the foundation region. It is important to note that in earthquake engineering applications, SSI effects can be beneficial because 
Target chamber:

- concrete cylinder

- $112 \mathrm{ft}$. tall

- $100 \mathrm{ft}$. diameter

- $6 \mathrm{ft}$. walls

- 47 million lbs

- $6 \mathrm{ft}$. mat foundation
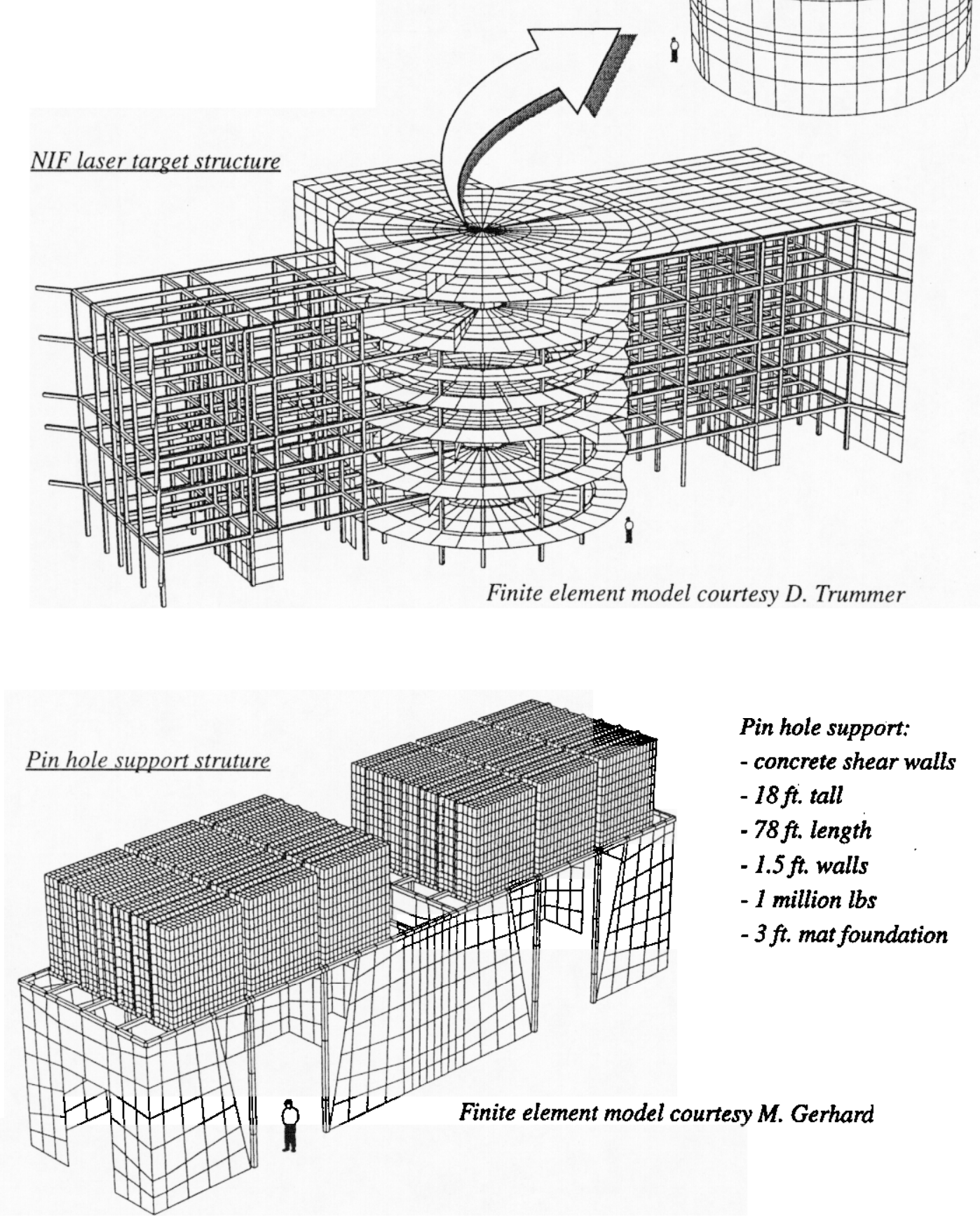

FIGURE 1. Preliminary configurations of selected NIF optical support structures. 


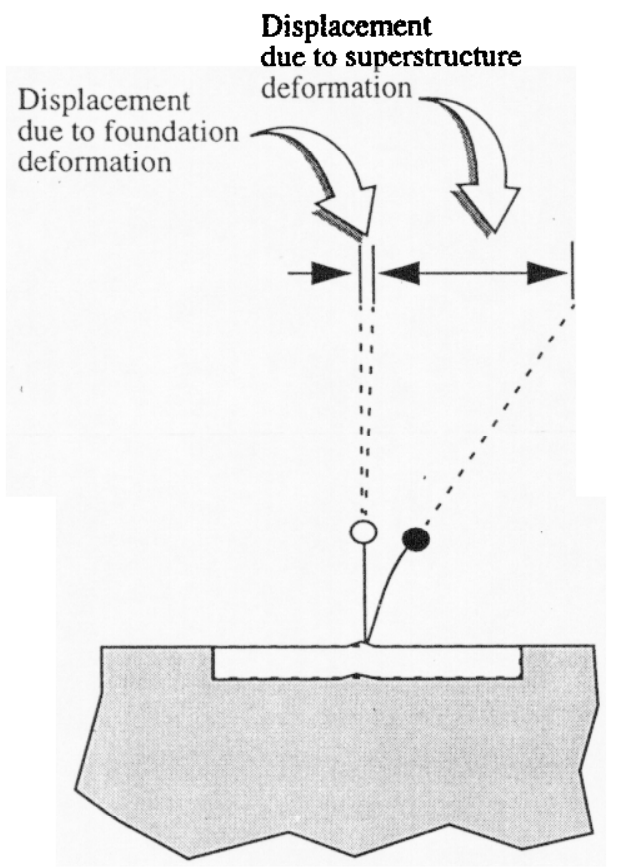

Light superstructure (behaves essentially like a fixed base structure)

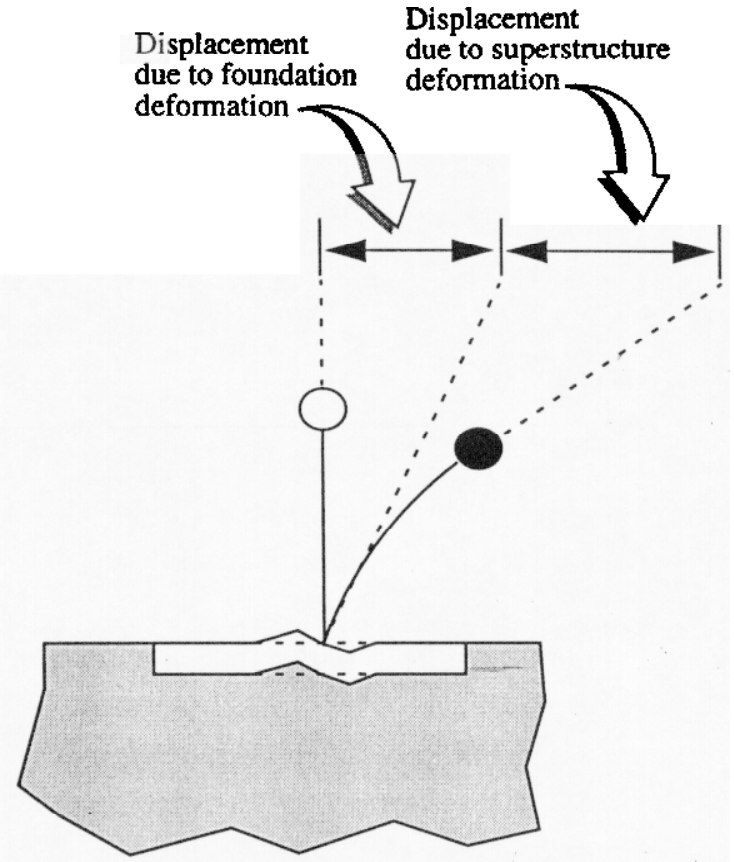

Massive superstructure (foundation flexibility a significant contributor to system deformations)

FIGURE 2. Relative contributions to superstructure displacements from foundation flexibility for light and massive superstructures.

increased flexibility can translate into lower force levels in the superstructure. For optical systems subjected to ambient vibrations, on the other hand, foundation flexibility will generally be detrimental because of an increase in system displacements.

The initial designs of the NIF optical support structures have been predicated on fixed base assumptions. These analyses essentially assume a rigid foundation system and neglect the displacement and deformation due to foundation flexibility. The fixed base analyses also assume identical support input motion. The primary objectives of the current study were to quantify the effects of SSI, to estimate the effect of the foundation flexibility on optical system displacement design margins, and to develop a simplified and expedient procedure which the structural analysts and designers could utilize for approximating the effects of SSI. 


\subsection{The ambient vibration environment at the NIF site}

The proposed NIF location at the Lawrence Livermore National Laboratory (LLNL) is in the eastern region of the LLNL site (see Fig. 3). The Livermore Valley is a sedimentary basin of approximately 500 foot depth at the LLNL site. Recently completed geotechnical studies for the proposed NIF location [1] have developed the soil profile for the site (see Fig. 3). The site soil parameters estimated from the geotechnical investigation are summarized in Table 1. There is a variable thickness, soft layer of soil at the proposed site which appears to be displaced soil from a previous construction. It is assumed in the current study that this soft layer will be excavated and removed. The nominal shear wave velocity for the site is around 1000 feet per second as indicated in Fig. 3.

Vibrations of the NIF optical arrays will be driven by the ambient environment at the proposed NIF location. In general, the ambient environment at any particular site is defined by a complex wave field which includes both surface wave and body wave components generated from a number of sources. Based on ambient ground motion studies performed by the LLNL Treaty Verification Program [2], a general observation which has developed is that at frequencies of $1 \mathrm{~Hz}$ and above, the ambient ground motion tends to be dominated by surface waves generated primarily by man-made surface disturbances (vehicles, running equipment etc.) while at frequencies below $1 \mathrm{~Hz}$ the ambient ground motion tends to be dominated by body waves generated by microseisms from natural sources.

In earthquake engineering applications, where the structural response to strong ground motion is of interest, it is typical to idealize the incident wave field as consisting of vertically propagating shear waves for SSI analyses. This approximation is most appropriate for deep, soft, soil sites, in which the incident wave direction bends more towards the vertical as the waves enter softer layers of soil near the surface (Fig. 4). For weak motion ambient vibrations, on the other hand, surface waves are of paramount concern since they tend to be the dominant factor in the ambient vibration wave field in the frequency range of interest for the NIF structures $(5-20 \mathrm{~Hz})$. The importance of surface waves in ambient vibrations is evident from the classical analytical solution of Miller and Pursey [3] for a sinusoidal oscillator on an elastic half space ${ }^{1}$. Miller and Pursey's work shows that for a sinusoidal surface oscillator, $67 \%$ of the radiated energy is transported in the form of surface waves confined to the near surface region, $26 \%$ of the energy is transported as shear body waves and the final $7 \%$ is transported as compressional body waves (Fig. 5). Another aspect for consideration has to do with the manner in which the different waveforms maintain their intensity with distance from the generation source. The decay of wave amplitude with distance which results from spreading of the wave strain field over an ever increasing volume, is referred to as "geometric damping". Ewing, Jardetzky and Press [4] have shown that the geometric attenution of body waves in an elastic half-space varies as $1 / r$ while the geometric attenuation of surface waves varies as $1 /(\sqrt{r})$. The geometric damping effect derived by Ewing et. al. is shown in Fig. 6 for body waves and surface waves. As indicated, the body wave geometric damping is significantly higher than

1. The results of Miller and Pursey's solution can be found in Richart, Hall and Woods, Vibrations of Soils and Foundations, Prentice Hall, 1970. 


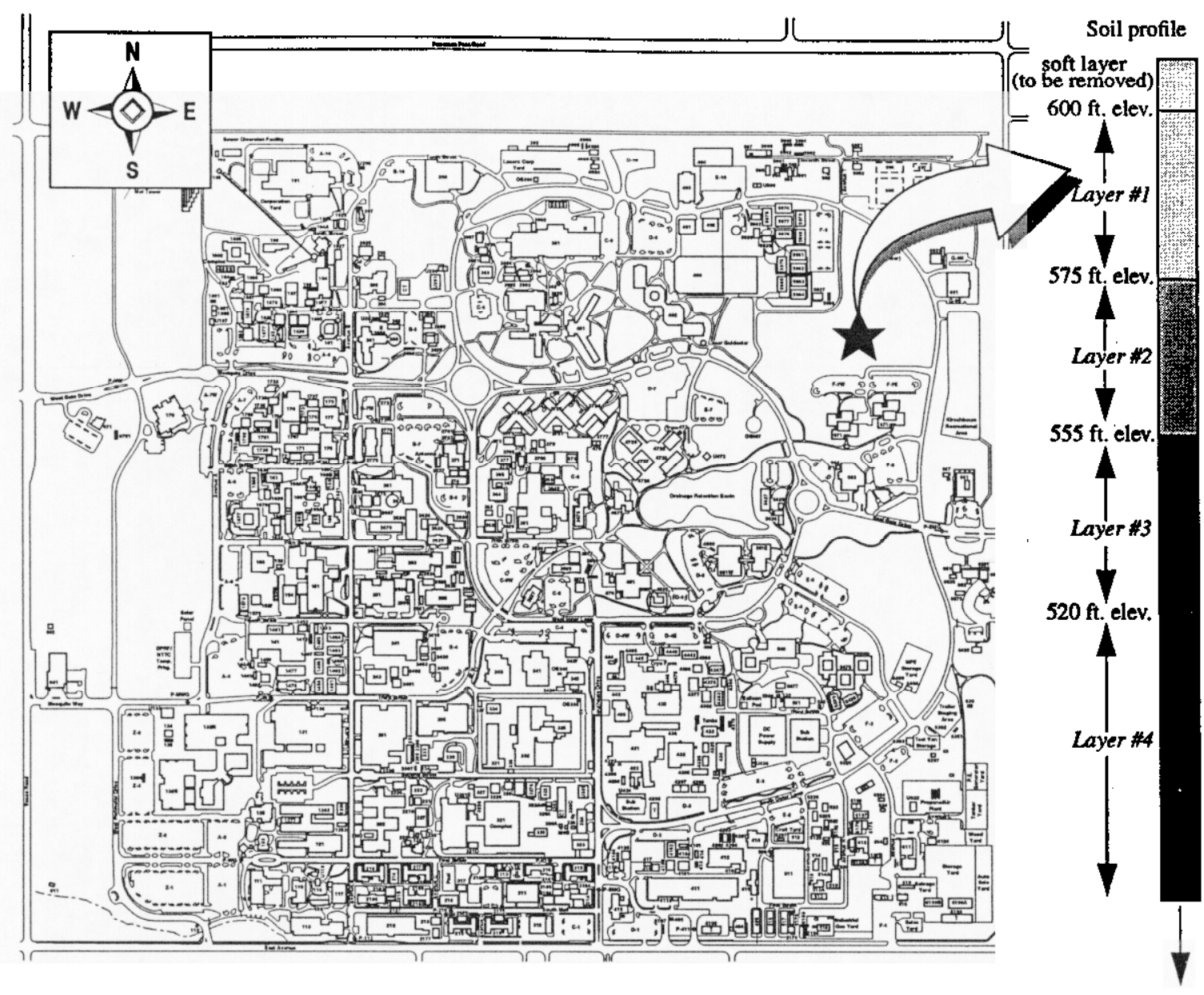

\begin{tabular}{|c|c|c|c|c|c|c|c|}
\hline \multirow[b]{2}{*}{ Layer } & \multicolumn{2}{|c|}{ Lame constants } & \multirow[b]{2}{*}{$\begin{array}{c}\text { Density } \\
\rho \\
\left(\mathrm{lb}-\mathrm{s}^{2} / \mathrm{ft}^{4}\right)\end{array}$} & \multirow[b]{2}{*}{$\begin{array}{c}\text { Poisson's } \\
\text { ratio } \mu\end{array}$} & \multicolumn{3}{|c|}{ Wave speeds } \\
\hline & $\begin{array}{c}\mathrm{Gmax}^{\mathrm{a}} \\
(\mathrm{psf})\end{array}$ & $\begin{array}{c}\lambda^{\beta} \\
\text { (psf) }\end{array}$ & & & $\begin{array}{c}\text { Dilatational } \\
v_{p}{ }^{c} \\
(\mathrm{ft} / \mathrm{s})\end{array}$ & $\begin{array}{c}\text { Distortional } \\
v_{s}^{d} \\
(\mathrm{ft} / \mathrm{s})\end{array}$ & $\begin{array}{c}\text { Surface } \\
v_{r}^{e} \\
(\mathrm{ft} / \mathrm{s})\end{array}$ \\
\hline$\# 1$ & $2.6 \times 10^{6}$ & $3.9 \times 10^{6}$ & 3.571 & 0.3 & 1596 & 853 & 768 \\
\hline$\# 2$ & $3.8 \times 10^{6}$ & $8.90 \times 10^{6}$ & 3.727 & 0.35 & 2104 & 1010 & 909 \\
\hline$\# 3$ & $4.5 \times 10^{6}$ & $1.05 \times 10^{7}$ & 4.037 & 0.35 & 2200 & 1060 & 950 \\
\hline$\# 4$ & $4.5 \times 10^{6}$ & $1.05 \times 10^{7}$ & 4.037 & 0.35 & 2200 & 1060 & 950 \\
\hline
\end{tabular}
a. $G=\frac{E}{2(1+\mu)}$
b. $\lambda=\frac{\mu E}{(1+\mu)(1-2 \mu)}$
c. $v_{p}=\sqrt{\frac{\lambda+2 G}{\rho}}$
d. $v_{s}=\sqrt{\frac{G}{\rho}}$
e. $v_{r} \cong 0.9 v_{s}$

FIGURE 3. Proposed NIF site at the Lawrence Livermore National Laboratory and the soil profile at the NIF site (soil profile from reference 1). 


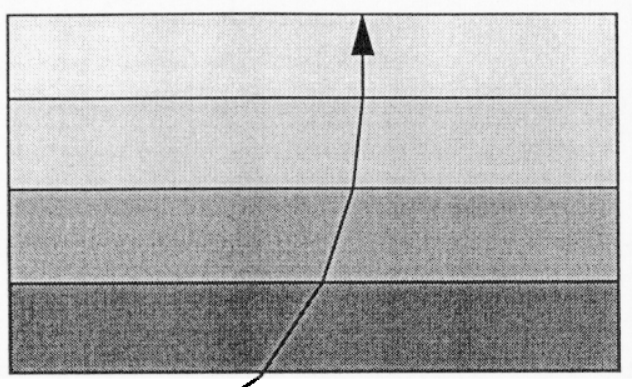

Shear body wave

Direction of propagation of body waves tends towards the vertical as wave refracts in softer layers



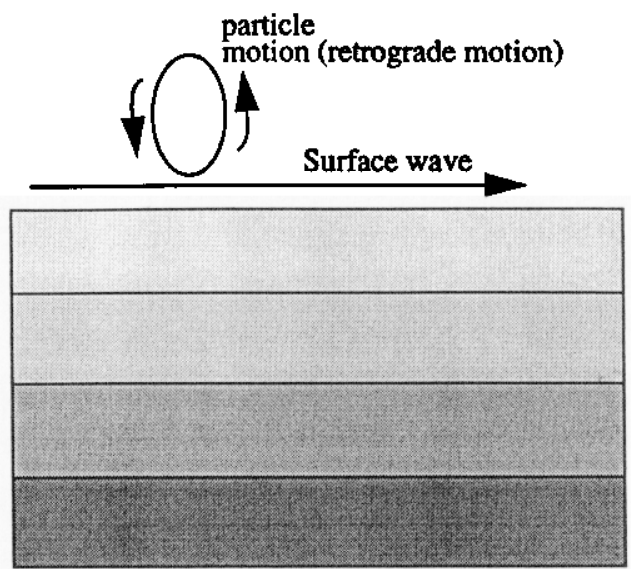

Weak ground motion from ambient noise

Strong ground motion from earthquakes

FIGURE 4. Idealized ground motion forms for earthquake motions and ambient motions.

\begin{tabular}{|c|c|} 
Wave type & $\begin{array}{c}\text { Energy } \\
\text { Distribution }\end{array}$ \\
\hline Rayleigh & 67 \\
\hline Shear & 26 \\
\hline Compression & 7 \\
\hline
\end{tabular}

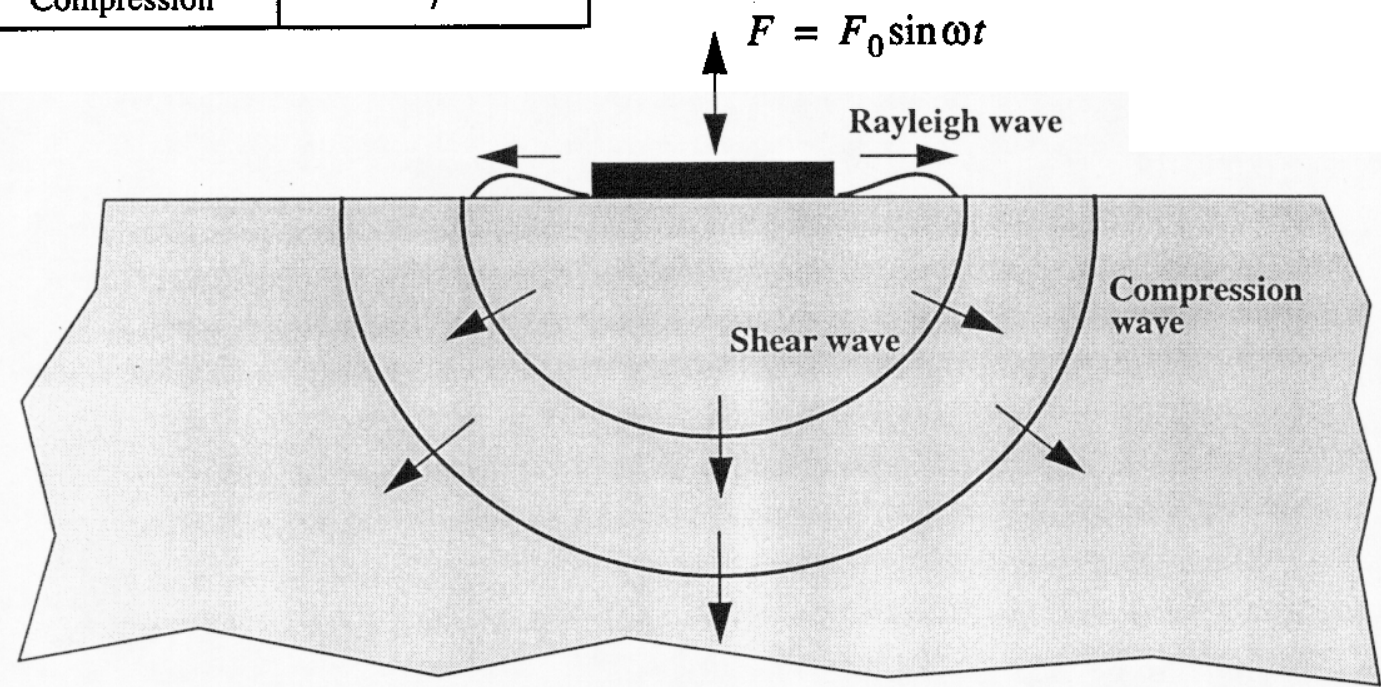

FIGURE 5. Radiating waveforms for a sinusoidal oscillator on an elastic half-space. 


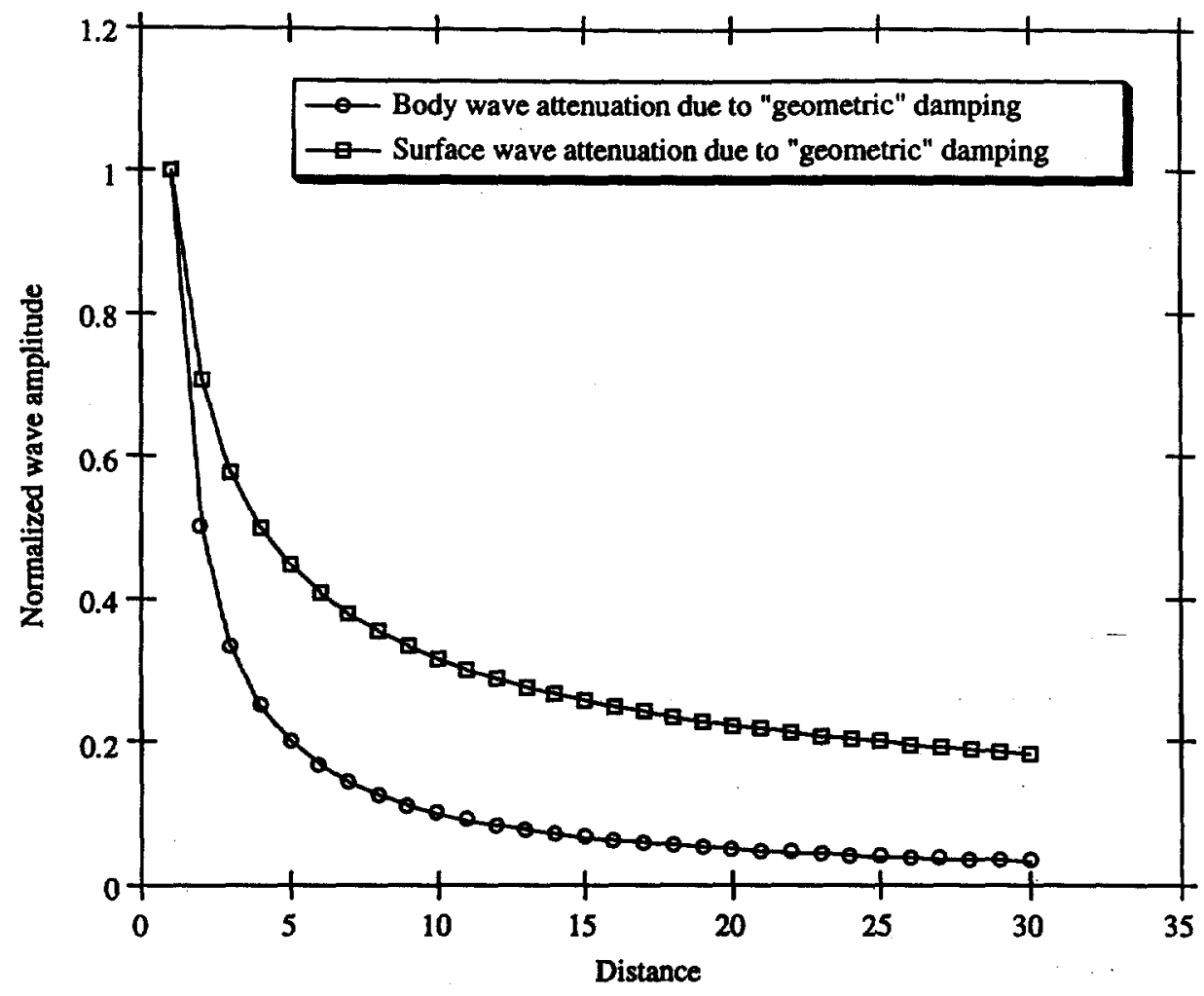

FIGURE 6. Wave amplitude attenuation with distance from the source (relationship based on Ewing, Jardetzky and Press [4]).

the surface wave damping. The physical basis for the significant difference in geometric damping is the fact that the body waves are spreading out over a half-space while the surface waves are only spreading out over a cylindrical area.

In summary, the work of Miller and Pursey demonstrates that a piece of reciprocating equipment running near the ground surface will tend to generate a wave field rich in surface waves, and the surface waves are significantly better than the body waves at maintaining their strength at farther distances from the source. To the first order, consideration of the stability of the NIF structures will be concerned with the effects of surface waves impinging on the structure and foundation system. 


\subsection{Finite element model of a structure-soil system}

The motion of the NIF structures in the ambient vibration environment will be of very small amplitude and the corresponding strains of the superstructures and the soil will be quite small. Thus the analysis will really be addressing a problem in what might be termed the linear "acoustical" vibration regime. This obviates the need to consider nonlinearities in the soil such as occur under earthquake loadings when the soil strains are large. It does however, lead to other complications. Most notably the fact that since soil strains are small, the elastic energy radiating from the vibrating superstructures will tend to propagate into the far field at distances remote from the superstructure. Appropriate accounting of this far-field radiation of the energy is a challenging problem in a time domain computer model of finite dimensions.

\subsection{Accounting for far-field effects in a finite size model}

The first issue which must be dealt with is the fact that the soil which supports the structure is of very large extent and wave energy radiates away from the vibrating structure into the far field at large distances from the structure. Computationally practical models can only account for a finite domain in a relatively small region surrounding the structure, and special procedures are necessary to account for the wave energy radiating into the far field. If a simple finite domain model with free boundaries is used, radiating waves are reflected at the boundary and energy can become trapped in the finite domain model, resulting in erroneous elastic strain energy build-up in the finite computational model as illustrated in Fig. 7c. In the case of strong earthquake ground motion this issue still exists, however, at the large soil strain levels associated with earthquake motions, hysteretic behavior of the soil is a large contributor to energy dissipation and a smaller percentage of the wave energy radiates to the far field. For seismic loading, a finite computational domain has often been utilized in which the domain boundaries are treated as free surfaces and a nonlinear hysteretic soil model is relied upon to dissipate radiating wave energy [5] before it can reflect back from the free surface and polute the problem solution. In the ambient vibration case, where soil strains are at the micro level, hysteretic energy dissipation is a much smaller contributor to the overall energy dissipation and energy radiating away from the structure to the far field accounts for proportionately more of the energy loss. In this case, a mechanism for precluding reflections at the boundary of the finite computational domain is required. Seed, Lysmer and Hwang comment on this issue in their classic paper [6] - "If the material damping in the soil is relatively high, energy radiating outwards from the vicinity of the structure is absorbed relatively quickly... However, if the soil damping is low, the effects of wave motions generated by the structure may be felt a considerable distance away". In the current study, a finite domain computational model was used for the structure-soil systems and a simple dashpot boundary was employed at the edges of the model in order to approximate a nonreflective, wave transmitting boundary (see Fig. 7d).

\subsection{The NIF structures time domain SSI model}

A simple two dimensional finite element model was employed for modeling the soil-structure system in the computational analyses. A generalized plane stress model was used in 
a)

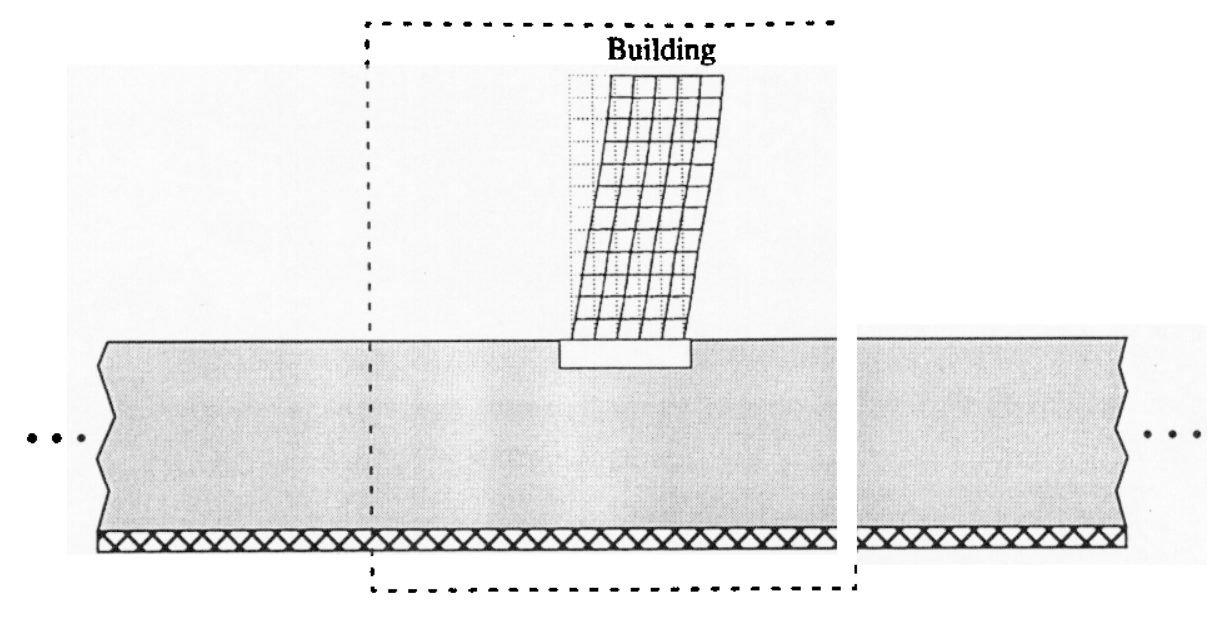

b)

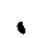

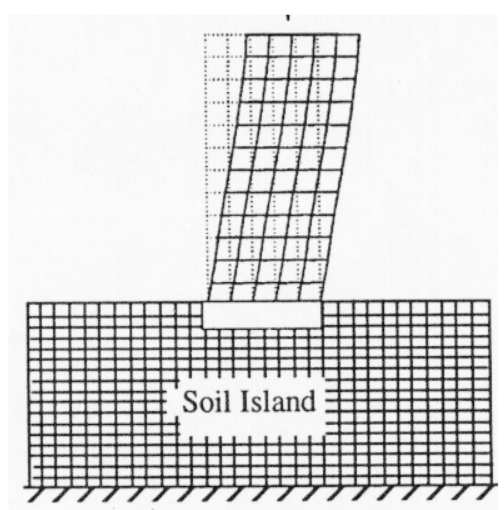

c)

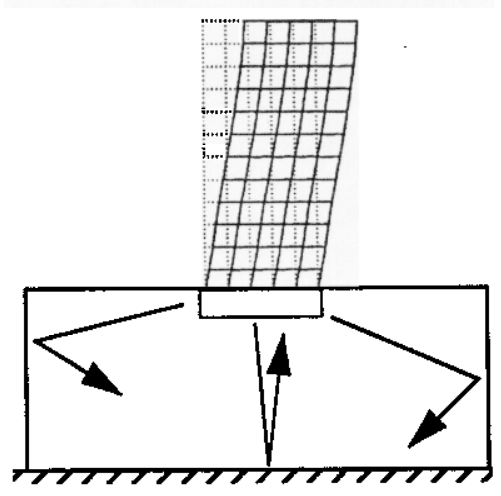

Without a transmitting boundary, radiated waves are reflected at the edges of the finite domain model

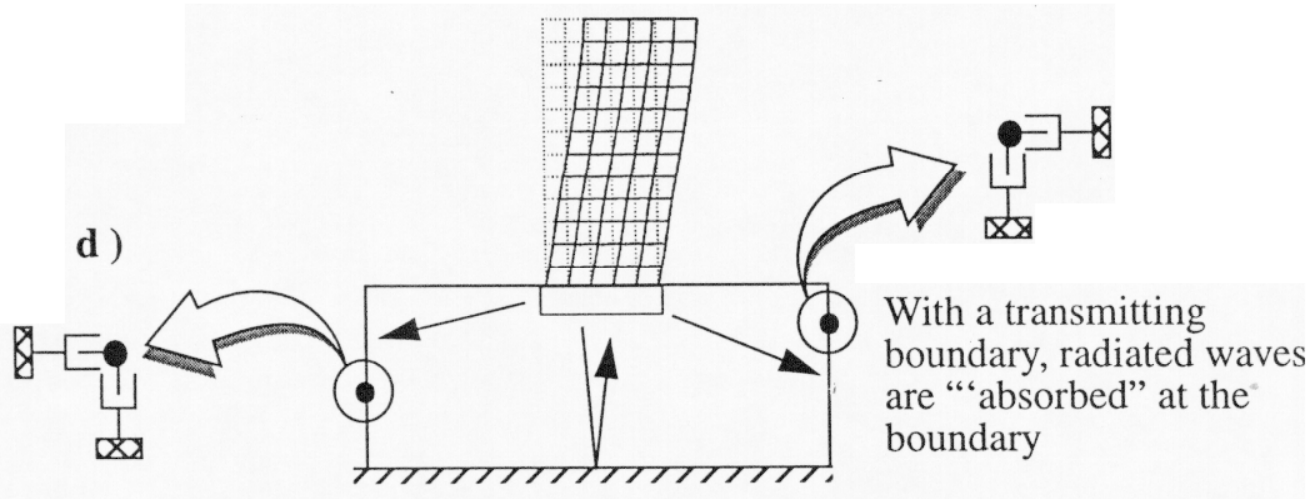

FIGURE 7. Numerical model of the building-soil system. a) Structure-soil system of large horizontal extent; b) finite domain model; c) trapped waves in finite model; d) unreflected waves in a finite model with dissipative boundary. 
the analysis so that the out of plane thicknesses of the respective components could be adjusted. For example, the thickness of the shear wall elements was taken as the actual physical thickness of the walls, while the thickness of the foundation mat and soil elements were set equal to an idealized slice of the supporting soil and foundation as shown schematically in Fig. 8. The contributing thickness of the soil and foundation was based on the physical widths of the shear wall structures and previous experience with planar model representations (Ref. 5). Based on the recommendations provided by Seed et. al. [6], the overall dimensions of the model were controlled by the lowest frequency (longest wavelength) wave which was to be accurately modeled and the discretization (i.e. the size of the elements) of the domain was controlled by the highest frequency (shortest wavelength) which was to be accurately modeled. The distance from the sinusoidal forcing function to the transmitting boundary and the distance from the sinusoidal forcing function to the mat foundation was required to be at least one wavelength distance based on the frequency of the sinusoidal function. This allows appropriate formation of the wave field before the absorbing boundary or foundation mat is encountered. Additionally, the physical dimensions of the finite elements were required to be $1 / 8$ th the wavelength of the shortest wave which was to be captured in the model. This requirement is based on the recommendation of Seed et. al. [6] and ensures the accurate representatiom of the high frequency waves (see Fig. 9).

For the current study, the NIF "periscope" structure was selected as the structure for completely coupled SSI evaluation. In its current design configuration, the periscope structure is massive and the lateral load resisting system consists of stiff shear walls. The stiff shear walls will deform in a flexural mode which will result in significant rotation of the walls with the potential for large deformation in the foundation. The periscope structure was selected for the SSI evaluation since its large mass will be one of the worst case special equipment structures for soil-structure interation. The idealized soil-structure system for the periscope structure is shown in Fig. 10a and the finite element model of the structure and soil system is shown in Fig. 10b. The Livermore site is situated on a sedimentary basin of variable depth and the depth of the soil column at any specific location on the LLNL site is hundreds of feet. For the NIF structures analysis, the soil column is modeled down to a depth of 500 feet.

\subsection{Energy dissipation in the computational model}

For strong motion earthquake applications it is generally necessary to account for the nonlinear stress-strain behavior of the soil. However, because the strain levels associated with ambient vibration are so small, the soil is expected to behave essentially in the linear regime and a linear elastic model was used for characterization of the soil throughout these studies. There will always be some degree of mechanical damping in the superstructure and the soil, even at low strain levels. To account for these additional damping mechanisms, a small amount of Rayleigh damping was employed in the computational model. With a mass and stiffness proportional representation of damping, the damping value is anchored at two frequencies and has a frequency dependent distribution throughout the frequency range. Figure 11 illustrates the variation of damping with frequency for the particular case in which the target frequencies are 3.3 and $1.0 \mathrm{Hertz}$ respectively. 


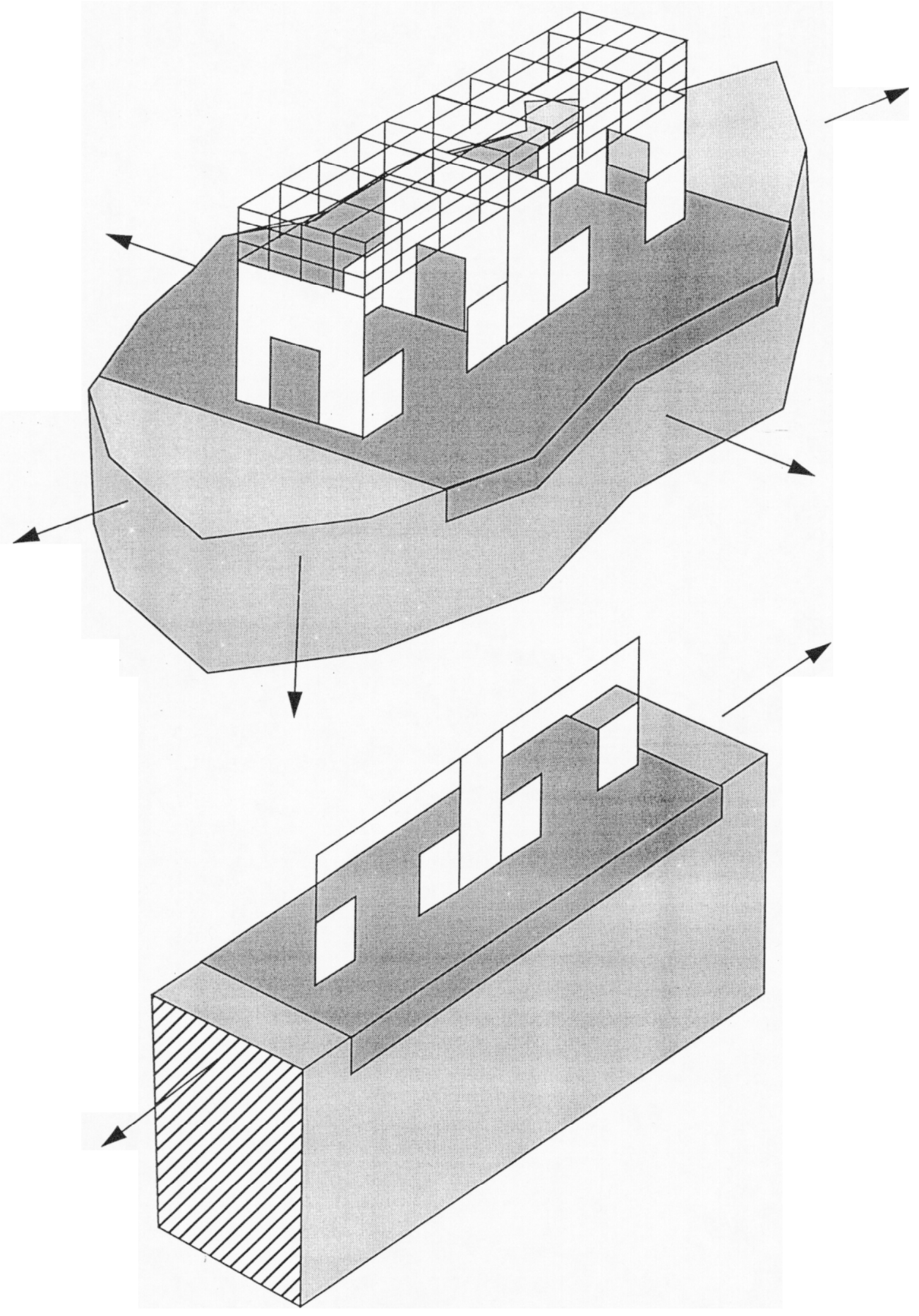

FIGURE 8. Three dimensional structure/soil system and 2D idealization. 

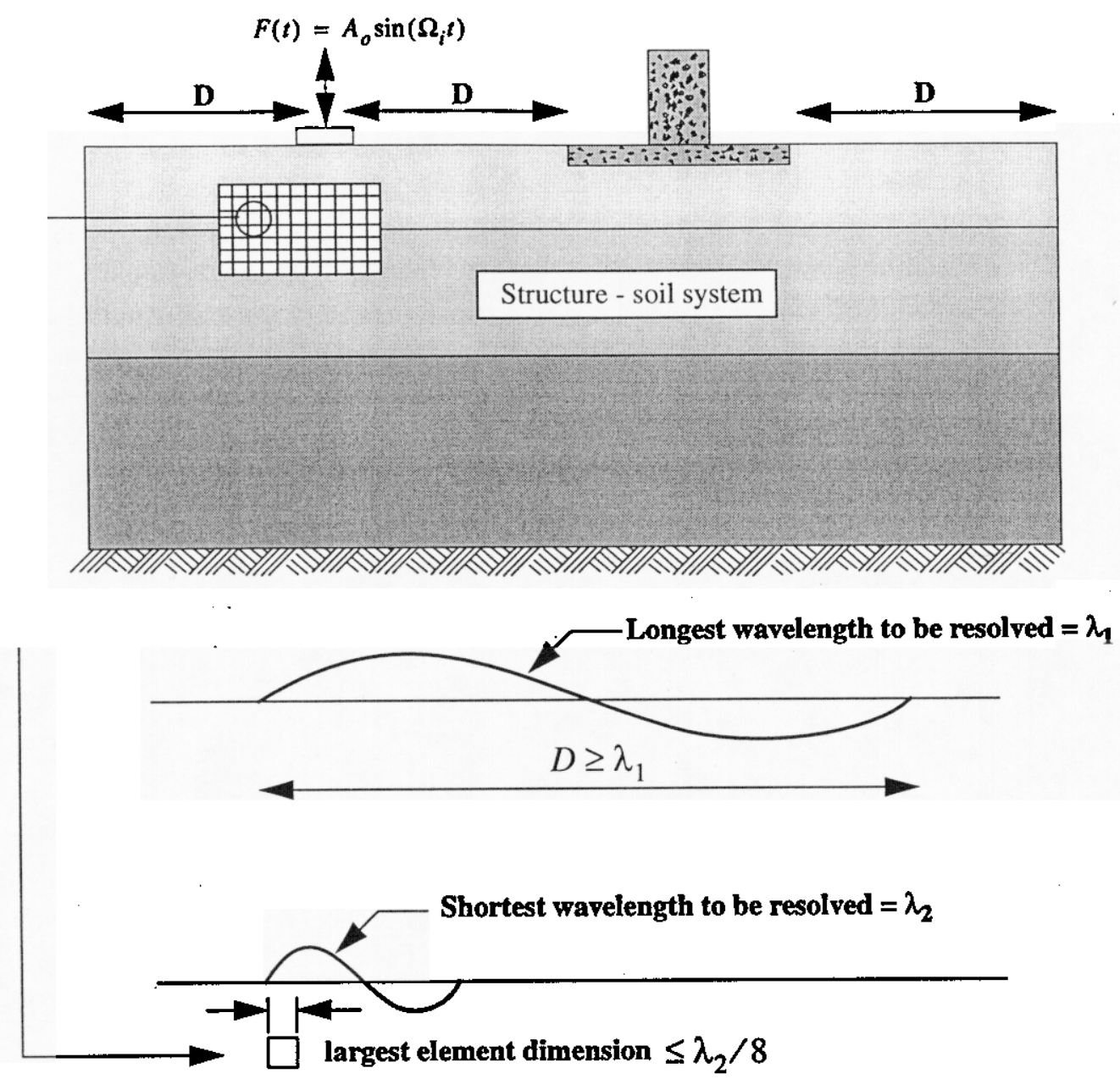

FIGURE 9. Controlling dimensions for the computational domain.

The dashpot constants for the nonreflecting boundary are determined from the simple viscous boundary developed by Lysmer and Kuhlemeyer [7]. In a finite element model, this boundary prescribes the velocity dependent nodal forces which act normal and tangential to the boundary, and the nodal force values are given by

$$
\begin{gathered}
N=\text { Area } \times \rho v_{p} \dot{u} \\
T=\text { Area } \times \rho v_{s} \dot{v}
\end{gathered}
$$

Where $N$ and $T$ are the boundary nodal forces which act normal and tangential to the bcundary respectively, Area is the tributary area surrounding the node, $\rho$ is the mass density of the soil, $v_{p}$ and $v_{s}$ are the compressional and shear wave velocities of the soil and $\dot{u}$ and $\dot{v}$ are the normal and tangential velocities of the node in the finite element model (Fig. 11). 


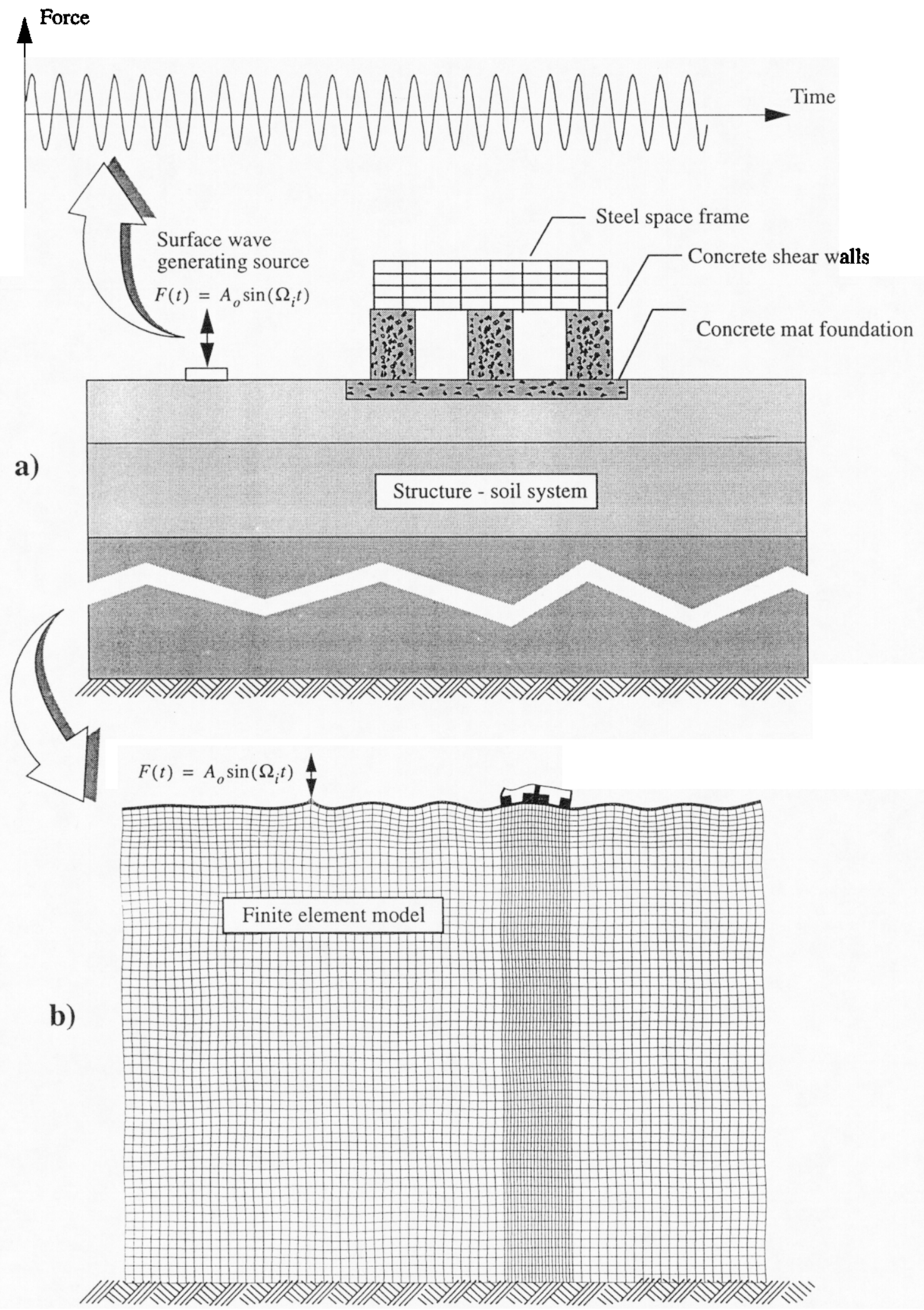

FIGURE 10. 2D approximation of the interaction of a concrete shearwall and the mat foundation and soil. a) Loading and soil/structure system; b) finite element model. 
The importance of the damping mechanisms is demonstrated from an analysis of a sinusoidal forcing function applied to an elastic half-space. For a forcing function with a frequency of oscillation of $5 \mathrm{Hertz}$, three analyses were performed. In the first case, the dashpot boundary and Rayleigh damping were not included (see Fig. 12), for the second case the dashpot boundary was included (Fig. 13) and for the third case both the dashpot boundary and Rayleigh damping (2\% damping) were included (Fig. 14). Comparison of the case in which the transmitting boundary was not utilized (Fig. 12), with the case in which the transmitting boundary was utilized (Fig. 13), clearly shows the significance of the energy radiating out of the finite domain model. Without the dashpots, energy is trapped in the domain and surface waves reflect back and forth through the model. With the transmitting boundary, the waves propagate to the model edges and are for the most part unreflected. Computer animation of the solution for the transmitting boundary model clearly shows the waves propagating through the edges of the model in an appropriate fashion.

Comparing the results for the cases of no Rayleigh damping (Fig. 13) and Rayleigh Damping (Fig. 14) shows that the Rayleigh damping has a very minimal effect on response.

Additional clear evidence of the importance of the transmitting boundary can be seen by examining the case in which the surface forcing function is suddenly turned off and the model continues to respond dynamically. Without the transmitting boundary (see Fig. 15), the model continues to ring as the elastic waves propagate back and forth in the model. When the transmitting boundary is included, on the other hand, the wave train effectively propagates out of the model and the domain becomes quiescient as indicated in Fig. 16. 



FIGURE 11. Sources of damping in the numerical model. a) Example of Rayleigh damping (5\% damping anchored at 0.3 and 1.0 second periods); b) nonreflecting boundary to account for radiation damping. 

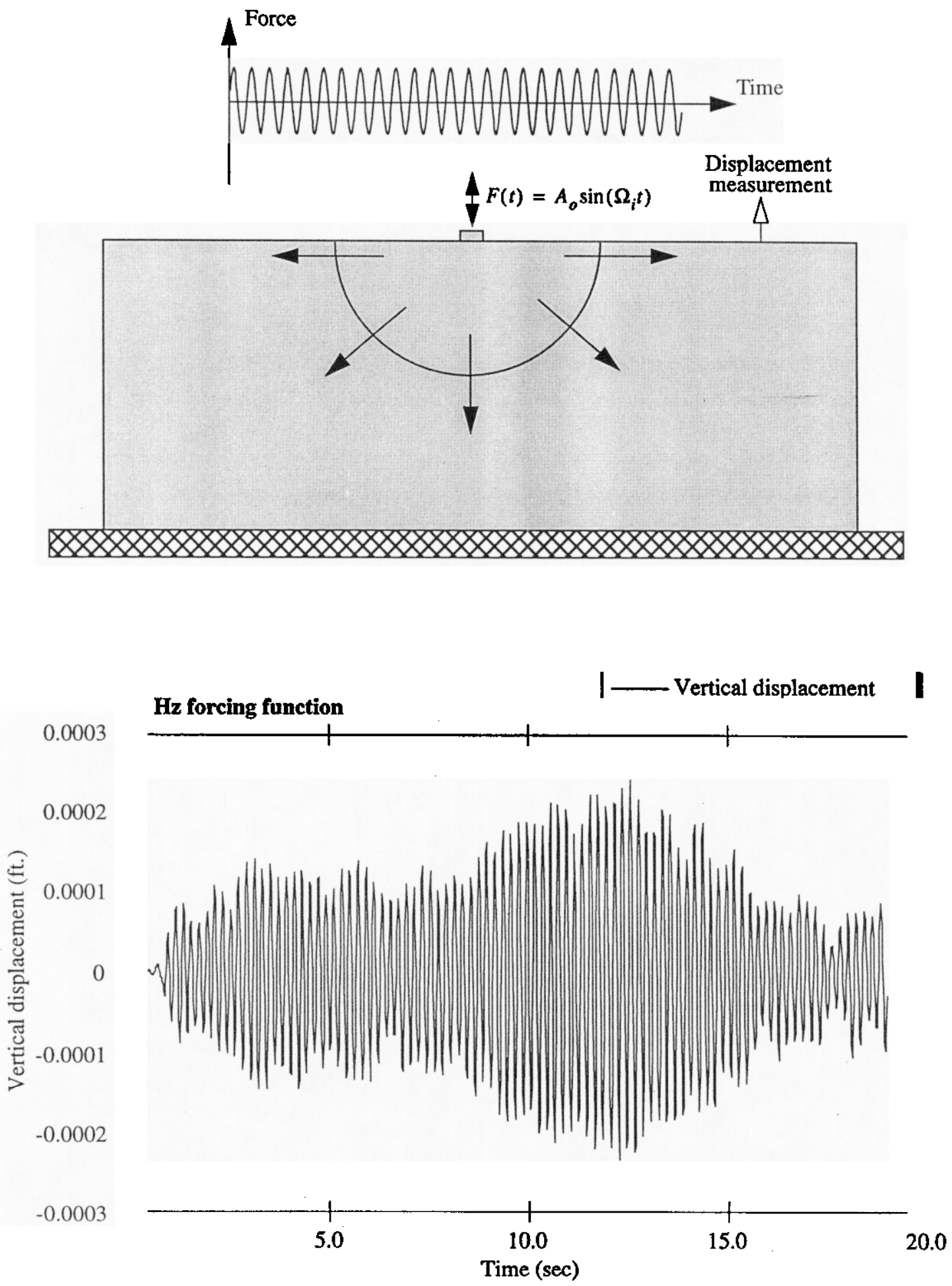

FIGURE 12. Transient response of a soil half-space to a sinusoidal surface forcing function finite domain without dissipative boundary and without Rayleigh damping. 

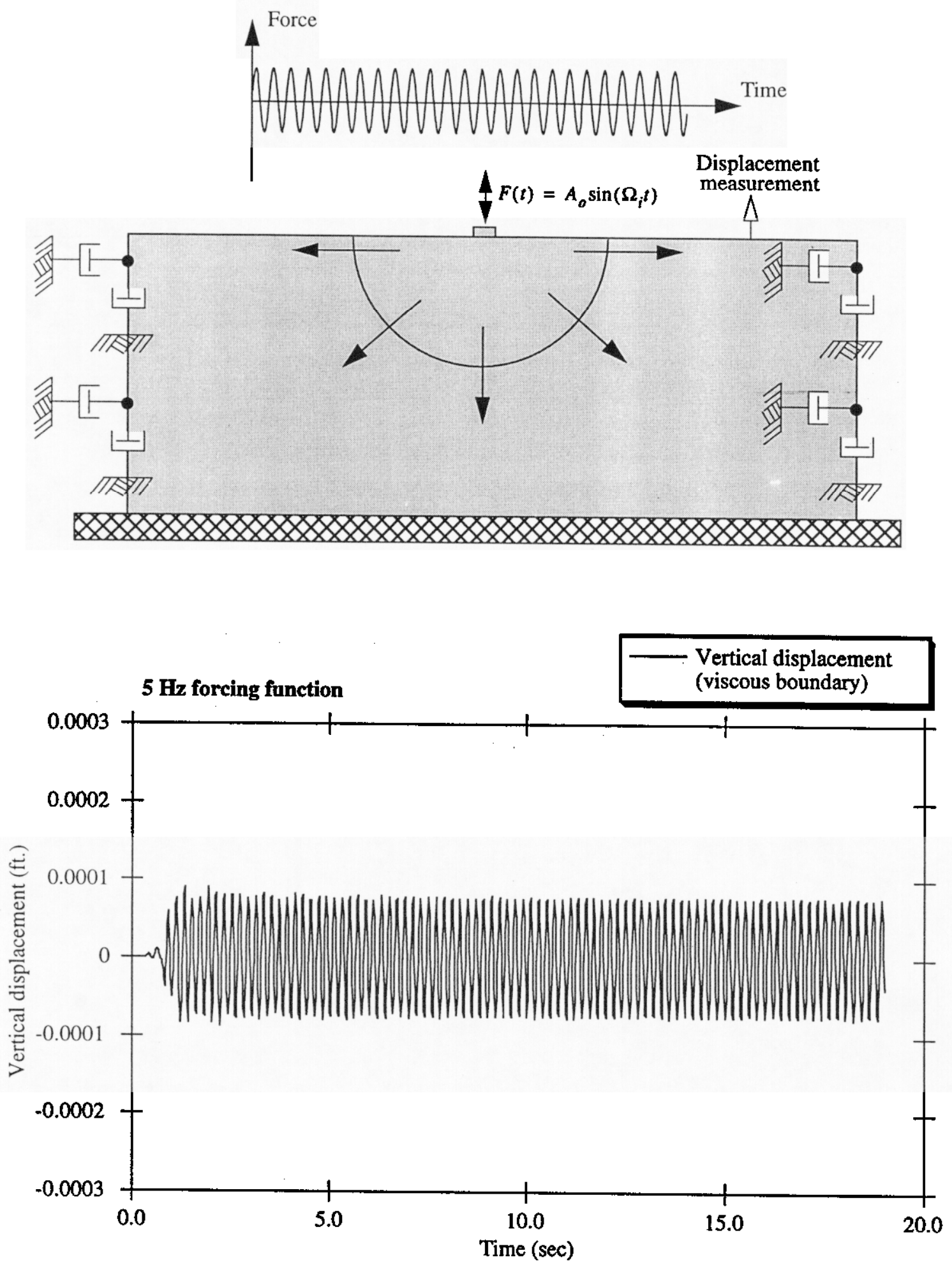

FIGURE 13. Transient response of a soil half-space to a sinusoidal surface forcing function finite domain with dissipative boundary and without Rayleigh damping. 


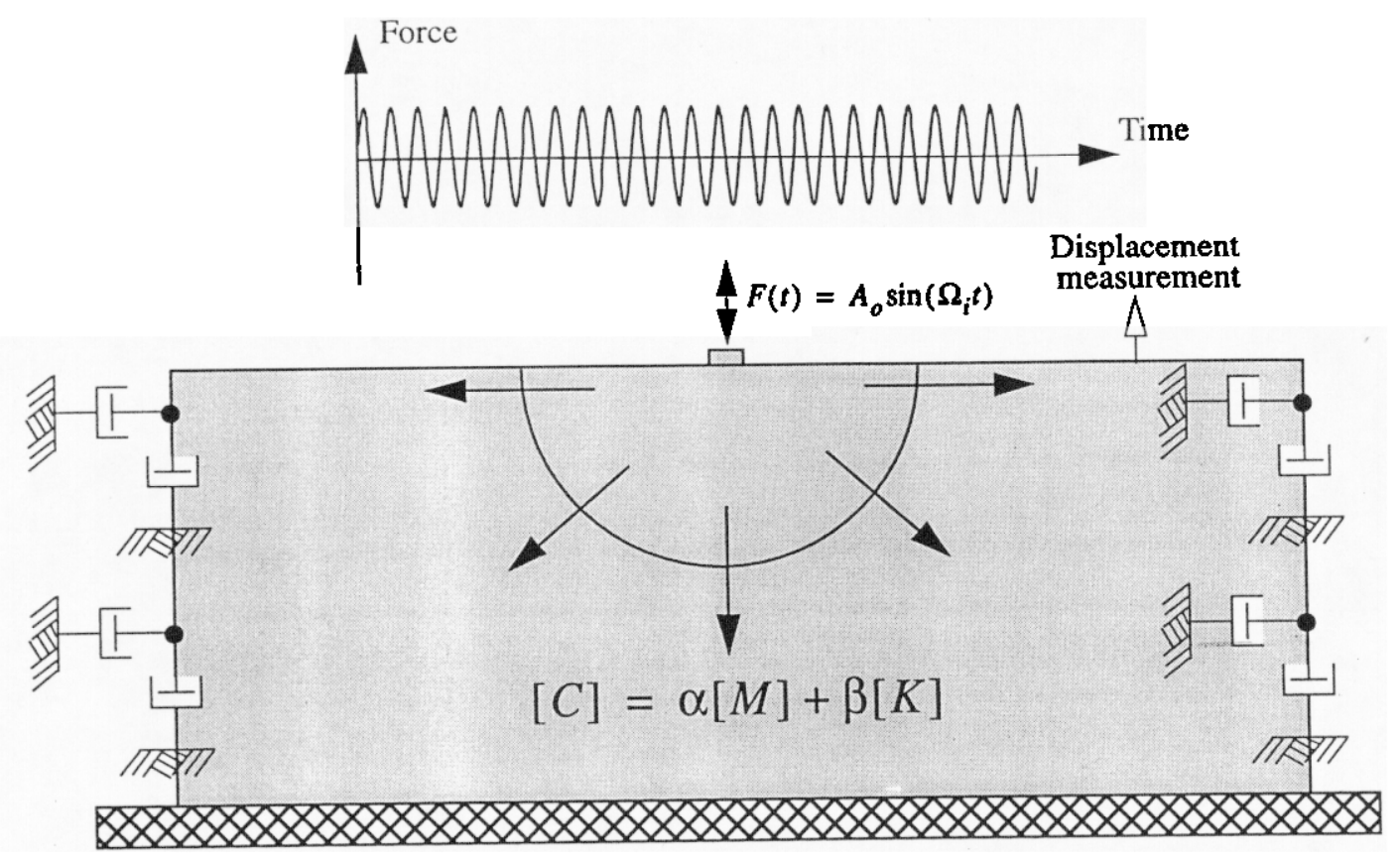

5 Hz forcing function $\quad \begin{aligned} & \text { Vertical displacement } \\ & \text { (viscous boundary and Rayleigh damping) }\end{aligned}$

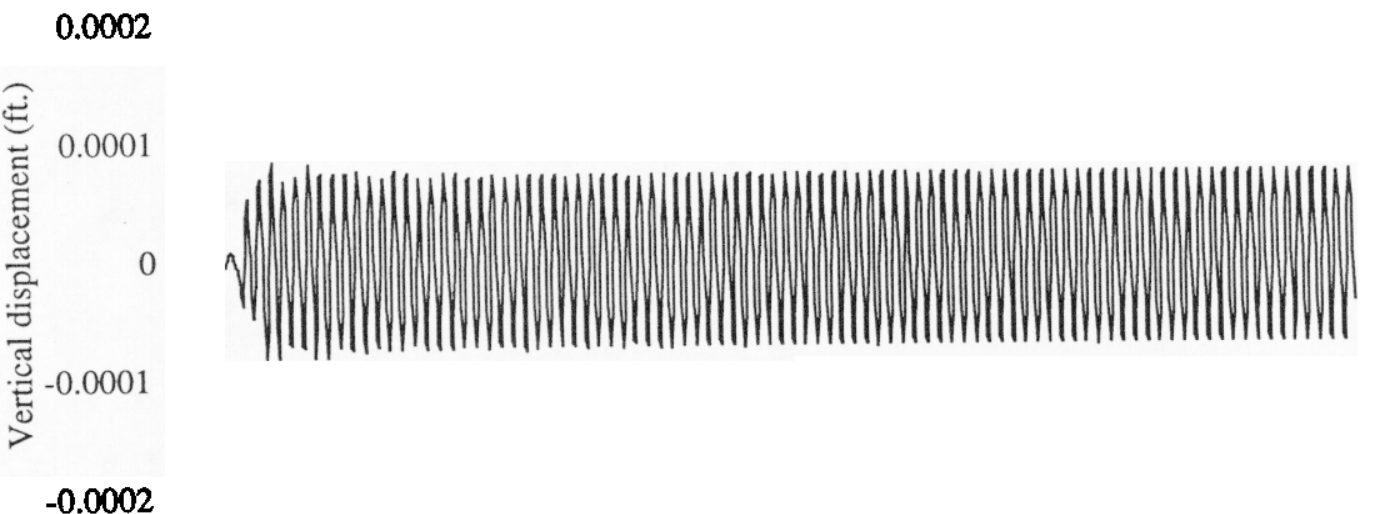

5.0

10.0

15.0

20.0

Time (sec)

FIGURE 15. Transient response of a soil half-space to a sinusoidal surface forcing function finite domain with dissipative boundary and Rayleigh damping. 



FIGURE 16. Transient response with a shut-off of the forcing function - without dissipative boundary and without Rayleigh damping. 



FIGURE 17. Transient response with a shut-off of the forcing function - with dissipative boundary and Rayleigh damping. 


\subsection{Frequency dependent scattering of propagating waves by an imbedded mat foundation}

Prior to evaluating the effects of SSI on the NIF superstructures, a series of analyses were performed in order to gain understanding of the influence of the three foot thick mat foundation on the free field motions. Four different computational models were constructed for four different forcing functions, each forcing function of a different frequency. The discrete frequencies considered included 5 Hertz (Fig. 17), 15 Hertz (Fig. 18), 35 Hertz (Fig. 19) and $50 \mathrm{Hertz}$ (Fig. 20). For each frequency two analyses were performed. The first analysis considered the vertical motion of a point on the soil half space when the foundation was absent, the second analysis considered the vertical motion of a point on the foundation when the foundation was included in the model. The time histories for the vertical displacements for each modeling case are given in the figures and the ratio of the vertical displacements of the foundation to the vertical displacements on the foundationless half space are shown in Fig. 21. The results in Fig. 21 show the effect of scattering of the incident waves. As the frequency increases and the wavelengths become shorter, the incident waves scatter as they impinge on the foundation mat and the response at the top of the mat is significantly less than the free field response. As shown in Fig. 21, at the 50 Hertz frequency, the foundation mat reduces the response of the free field by a factor of about 0.38 .

The displaced shape of the model at selected time steps for the 50 Hertz forcing function is shown in Fig. 22 and Fig. 23 for the case of a mat foundation and no mat foundation respectively. Inspection of the displaced shapes clearly shows the attenuation of the motion. Figure 23 shows a snap shot at the same instant in time, it is noted that the wave train in the case in which the foundation is included has traveled farther towards the right side of the domain. This is a result of the fact that the wave speed in the concrete is higher than the wave speed in the soil and thus the wave has traveled a greater distance.

These results indicate the degree to which the foundation isolates the superstructures from the free field ambient ground vibrations. The three foot foundation has essentially no effect in the $5 \mathrm{Hertz}$ range, where the wave lengths are large relative to the foundation dimensions. In the $50 \mathrm{Hertz}$ and above range, where the dimensions of the waves become short relative to the foundation, the mat foundation becomes an effective scatterer of the incident surface waves and a significant reduction in free field motion is realized. 

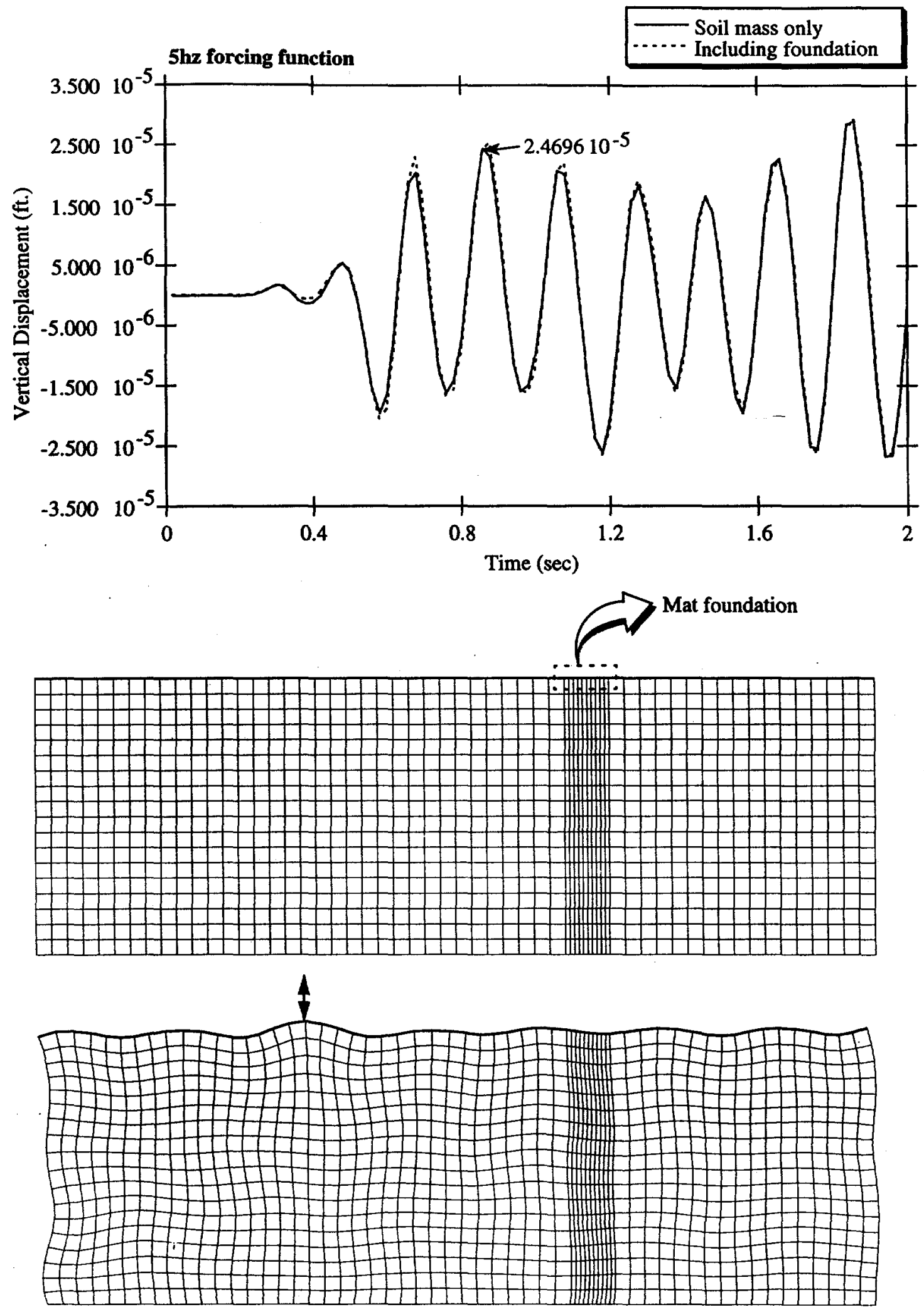

FIGURE 18. Foundation scattering for a $5 \mathrm{~Hz}$ forcing function. 

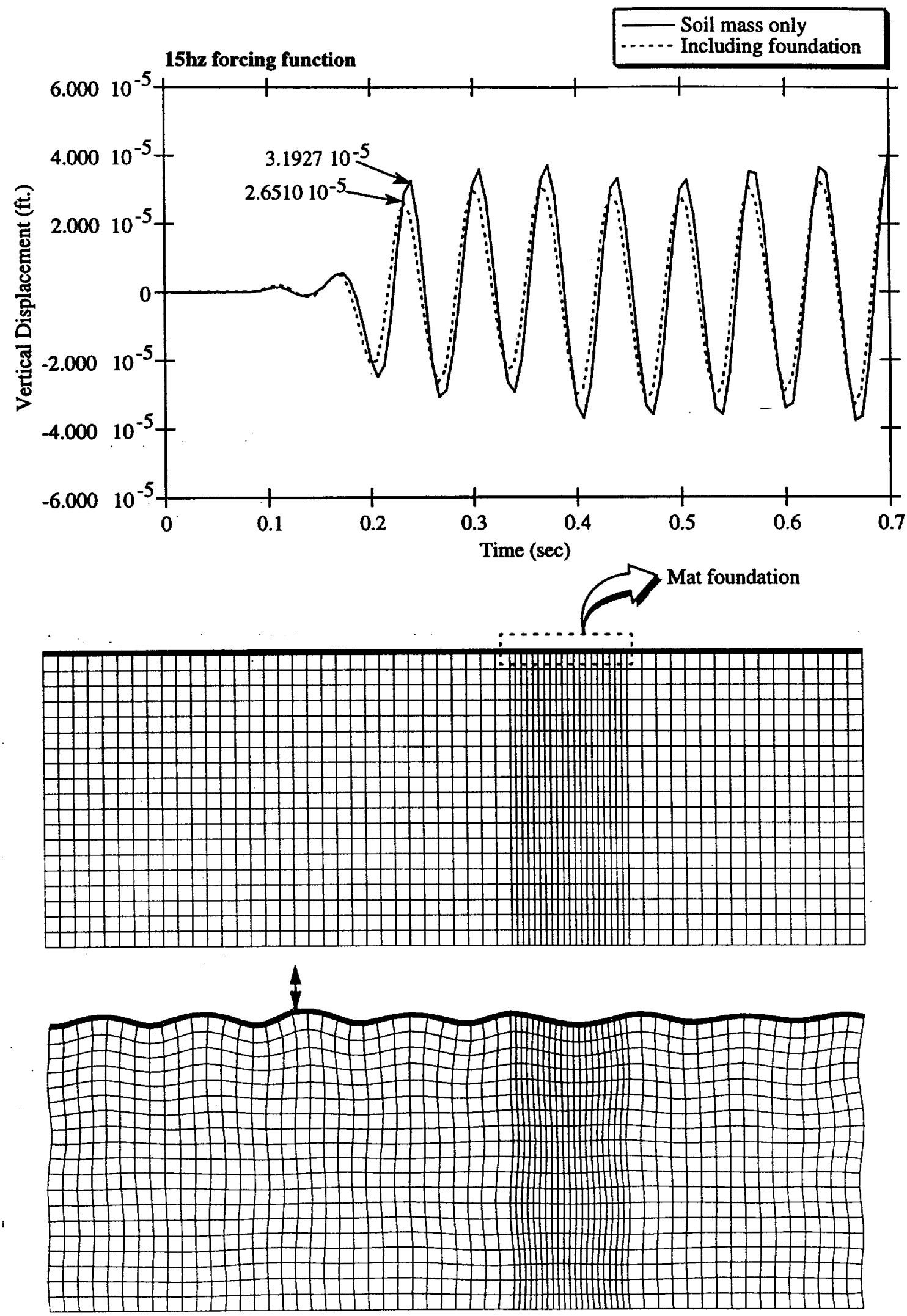

FIGURE 19. Foundation scattering for a $15 \mathrm{~Hz}$ forcing function. 

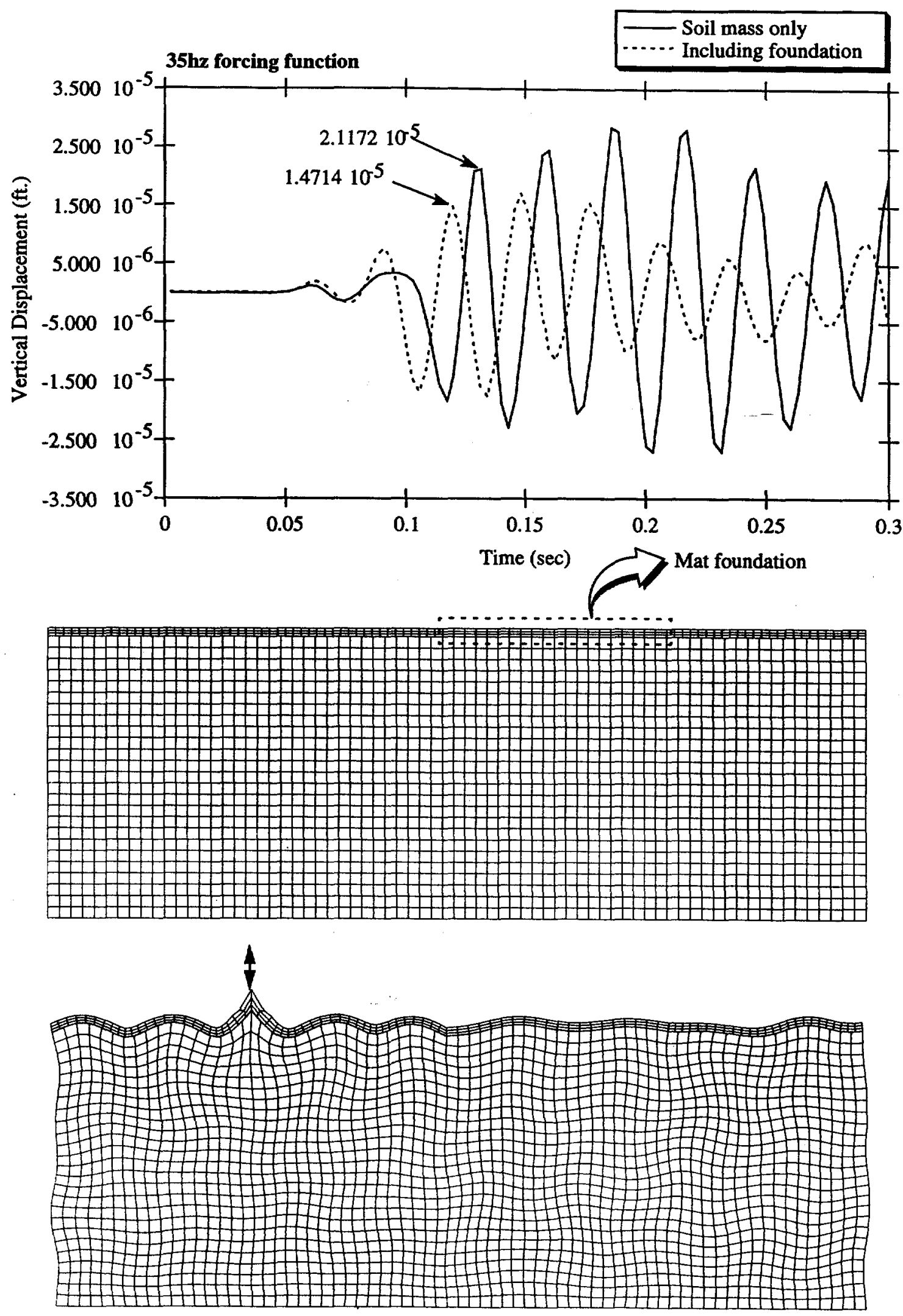

FIGURE 20. Foundation scattering for a $35 \mathrm{~Hz}$ forcing function. 

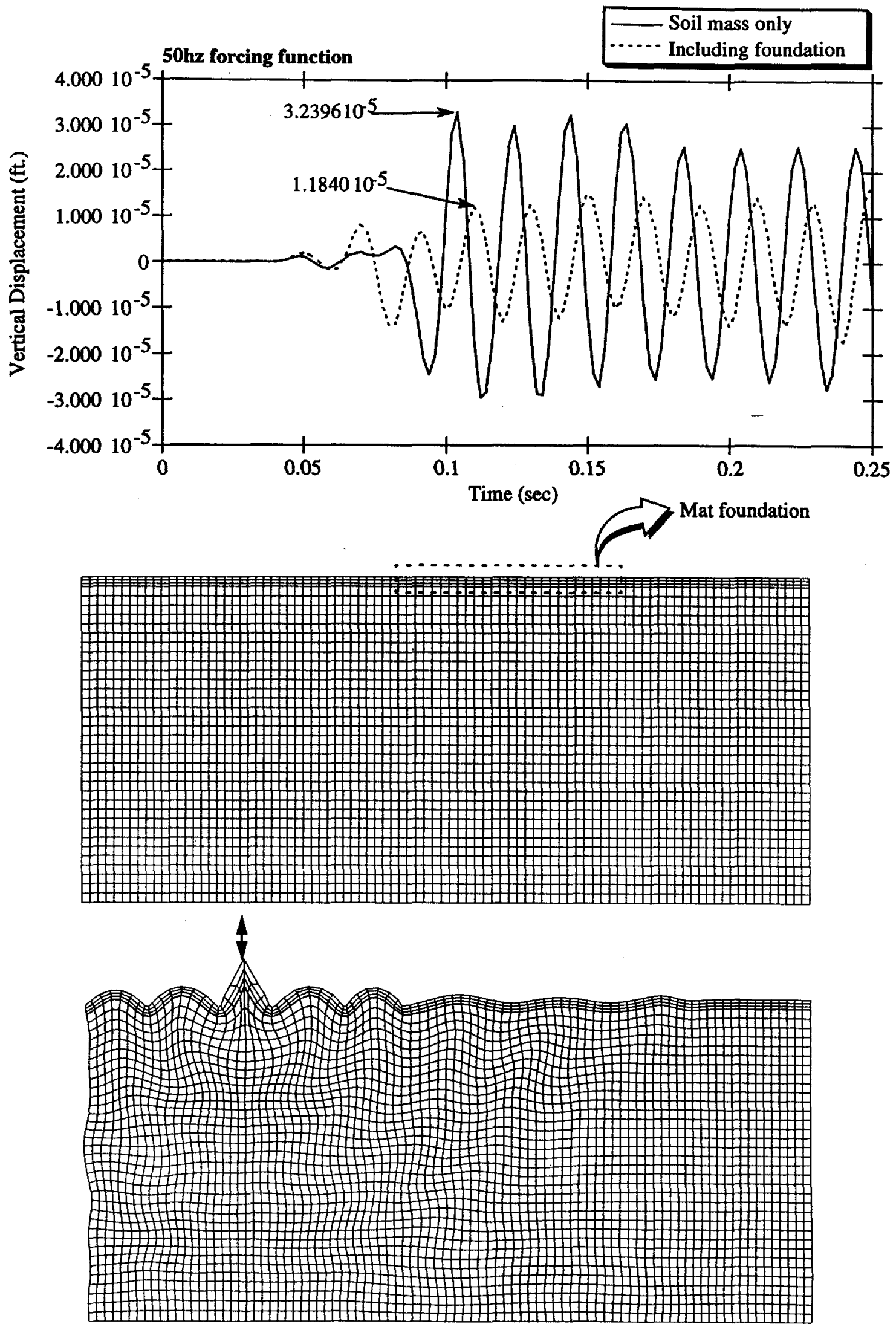

FIGURE 21. Foundation scattering for a $50 \mathrm{~Hz}$ forcing function. 


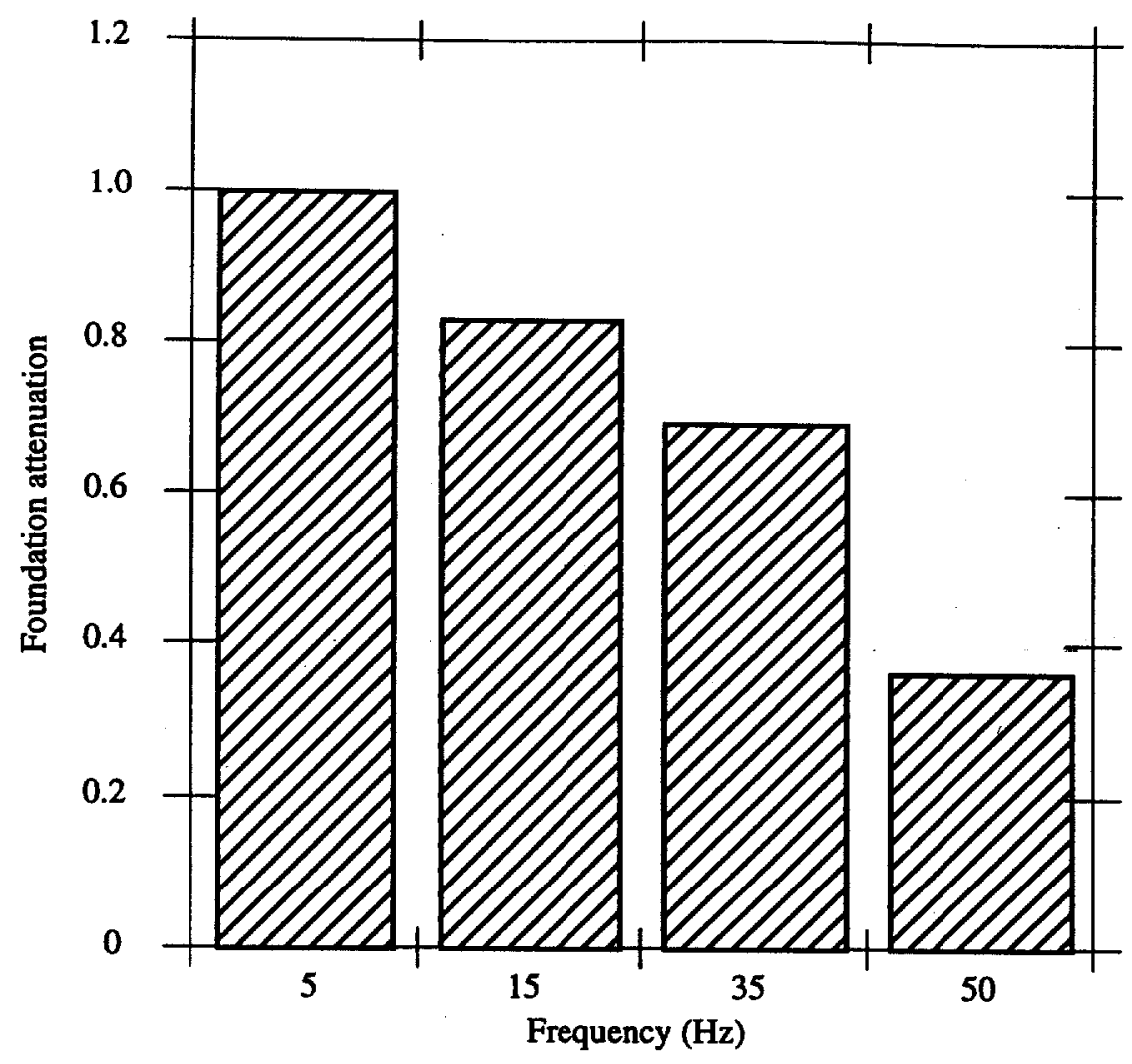

FIGURE 22. Foundation attenuation as a function of frequency. 



a)

b)

FIGURE 23. Response of a soil half space to a sinusoidal forcing function. a) Including a three foot concrete mat foundation; b) without the mat foundation. 

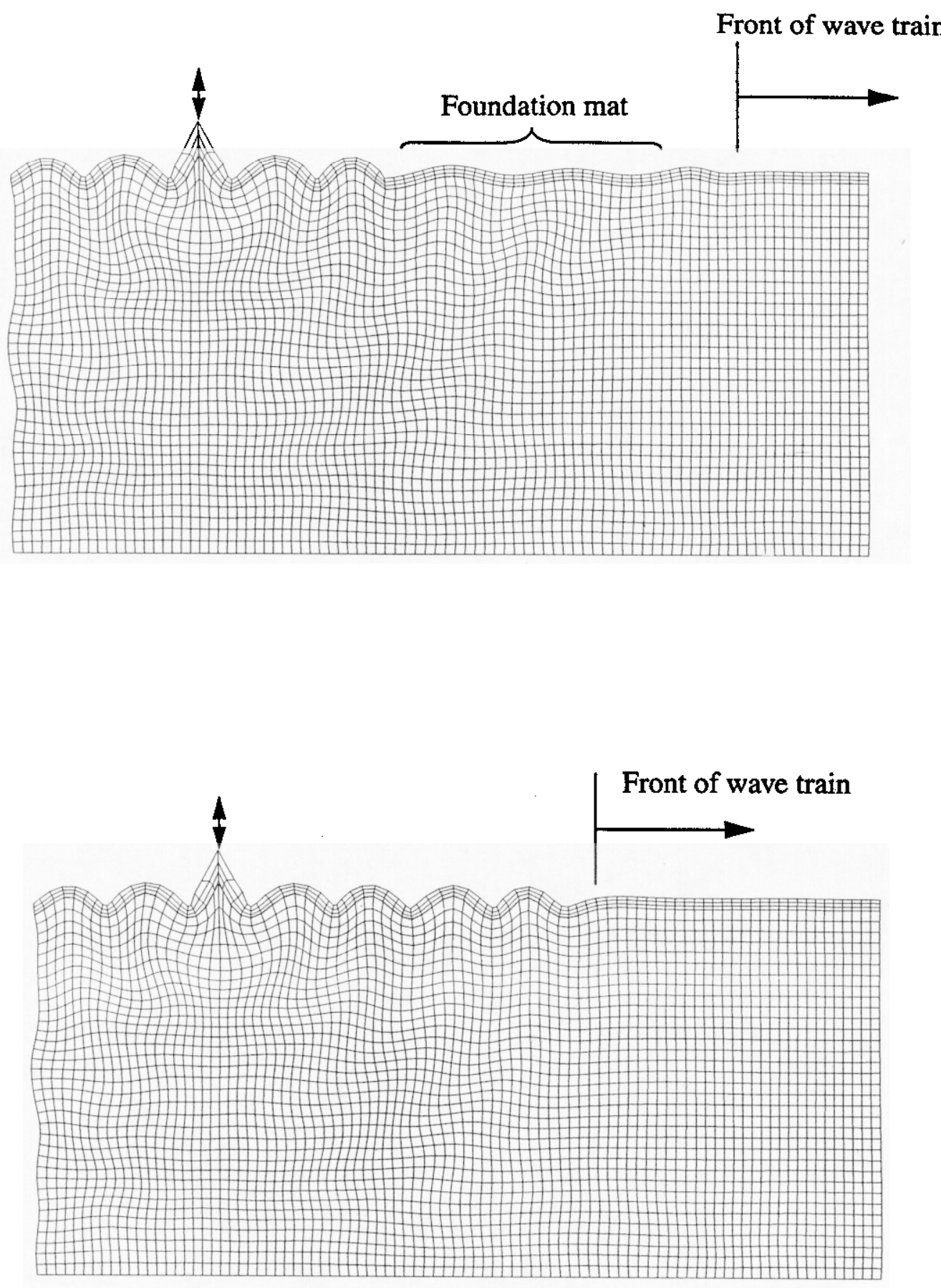

FIGURE 24. Passage of wave train in soil with and without the mat foundation. 


\subsection{Assessment of the influence of soil-structure-interaction}

The influence of soil-structure interaction on the displacements of the NIF superstructures was investigated by comparison of an uncoupled, fixed base analysis of the periscope structure with a fully coupled SSI analysis for the structure.

The frequency of the first transverse (i.e. in the long dimension of the structure), fixed base mode for the periscope structure was computed by Los Alamos National Laboratory engineers to be 14.1 Hertz based on a very detailed three dimensional model of the shear wall and space frame structure. Sommer at LLNL developed a less detailed three dimensional model and obtained a fundamental transverse frequency of $15.5 \mathrm{Hertz}$. A simplified two dimensional idealization of the periscope structure is shown in Fig. 24. In the two dimensional model, use was made of the fact that the steel frame is flexible in overall bending compared to the stiffness of the shear walls and the primary effect of the steel frame will be to couple the transverse motions at the tops of the shear walls. The coupling is a result of the fact that the steel members are quite stiff axially and will therefore enforce displacement compatability for the tops of the shear walls. This aspect of the structure was incorporated by including horizontal elements which were stiff axially but contributed small bending stiffness (see Fig. 24). The fundamental frequency of the two dimensional model was $15.4 \mathrm{Hertz}$ which correlates well with the frequencies obtained from the three dimensional models.

For the uncoupled analysis, the soil system was first analyzed without the superstructure or mat foundation (see Fig. 25). Based on previous studies for NIF structures, it was estimated that the fundamental mode of the periscope structure would decrease from the 15 Hertz of the fixed base model to somewhere in the 10 to 13 Hertz range for the structure founded on the foundation mat and soil system. As pointed out by Professor Costantino in his independent review of NIF SSI issues, the fundamental rocking mode of the structure should have the largest effect on soil-structure interaction and thus the predominant frequency range of interest for SSI is expected to be in the 10 to 12 Hertz range. To investigate the dynamic response in this frequency range, a sinusoidal surface oscillator of frequency $10 \mathrm{Hertz}$ was applied to the surface of the soil as shown in Fig. 25. For the decoupled analysis, the horizontal and vertical acceleration time histories at the superstructure location are saved and used as input to a fixed base analysis of the superstructure (Fig. 25), and input motion is applied uniformly over the entire foundation. This is commensurate with the assumptions invoked in the fixed base structural analyses which have been performed for all of the special equipment structures.

For the fully coupled SSI analysis, the same sinusoidal oscillator is applied to the soil surface and the superstructure response is determined directly in the fully coupled model (Fig. 26). From inspection of the deformation of the structure and foundation system for this particular structure, an important observation can be made (see Fig. 27). The wavelength of the surface waves at this relatively high frequency are quite short as can be seen in Fig. 27 and Fig. 28. Because of the short wavelength, there is a pronounced rotational component of the ground motion in this frequency range. In fact, other than the horizontal translations due to the horizontal component of ground motion, the most significant contributor to displacements at the top of the structure appears to be the rotational component 



Fundamental mode frequency $=15.4 \mathrm{~Hz}$

FIGURE 25. Idealized planar model of the periscope superstructure and the fundamental mode of vibration.

of the ground motion. Another way of looking at this is that the assumption of uniform support motion is quite invalid since the motion of the soil mass across the foundation mat varies greatly.

In order to determine the influence of SSI and rotations (i.e. variable foundation motion) of the ground on the superstructure deformations, the displacement at the top of the center shear wall, measured relative to the base of the shear wall, was computed for both analyses. The relative displacement measurement is shown in Fig. 29. It needs to be emphasized that when evaluating the effects of SSI, it is essential that relative displacements be considered. Total displacements can be completely dominated by long wave length, low frequency motions, even though these low frequencies contribute little to the interaction between the structure and the soil. The NIF superstructures have been purposefully designed to be so stiff that they will essentially ride as a rigid body for these low frequency 

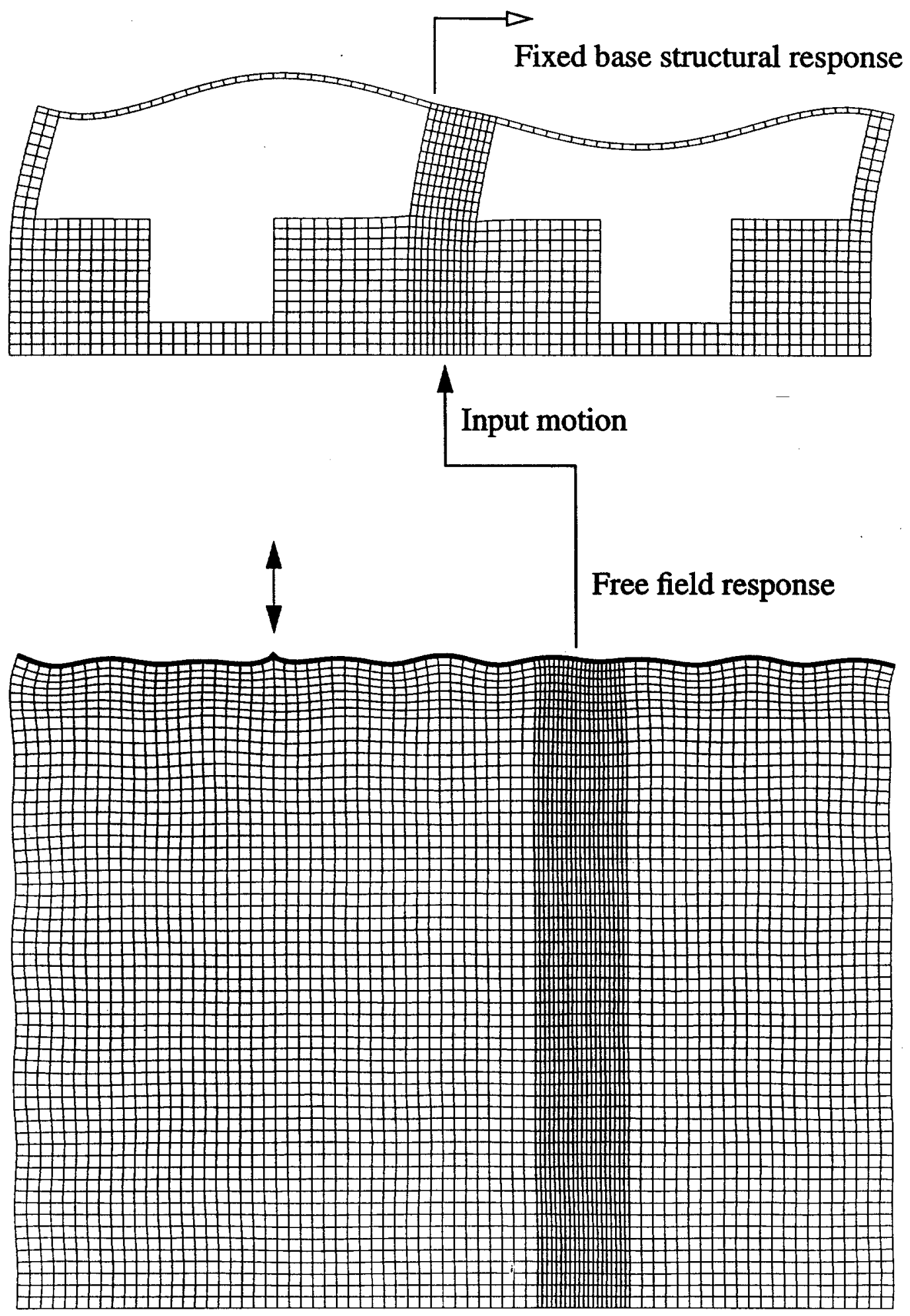

FIGURE 26. Decoupled analysis of the structure/soil system (neglects SSI effects). 
waves. Consequently if total displacements are considered, the erroneous conclusion that SSI effects are negligible may be reached. Moreover, relative deflections are of paramount concern when considering the deflections between adjacent optical structures situated on a common foundation. Long wavelength, low frequency motions will result in little relative deflections between adjacent structures, even though the low frequency drives the large absolute displacements. This observation is particularly important for the NIF structures, because the existing PSD defining design ambient vibrations currently has significant energy all the way to zero period. The low frequency content in this spectra will completely dominate the absolute deflections, and thus SSI effects (which occur in the 10-13 Hertz range) will be masked when the absolute deflections are considered. This issue arose when Kleinfelder first presented results for their SSI analyses in terms of absolute displacements, which gave the misleading conclusion that SSI could actually help reduce structural displacements, when in fact relative displacements were signficiantly increased.

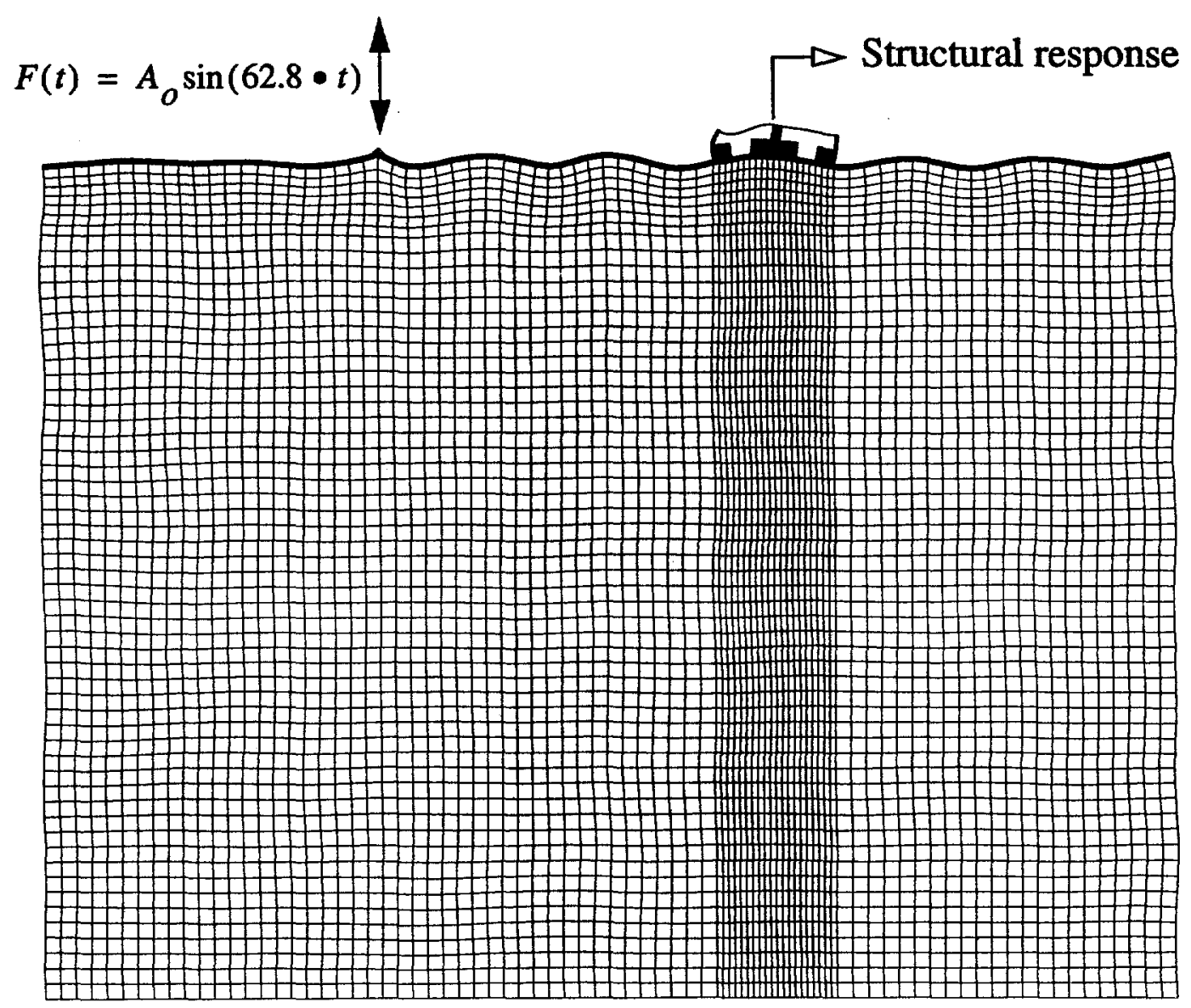

FIGURE 27. Fully coupled analysis of structure/soil system (includes SSI effects).

The relative deflections at the top of the center shear wall, as computed from the decoupled and fully coupled analyses, are shown in Fig. 30. In terms of RMS values, the RMS 

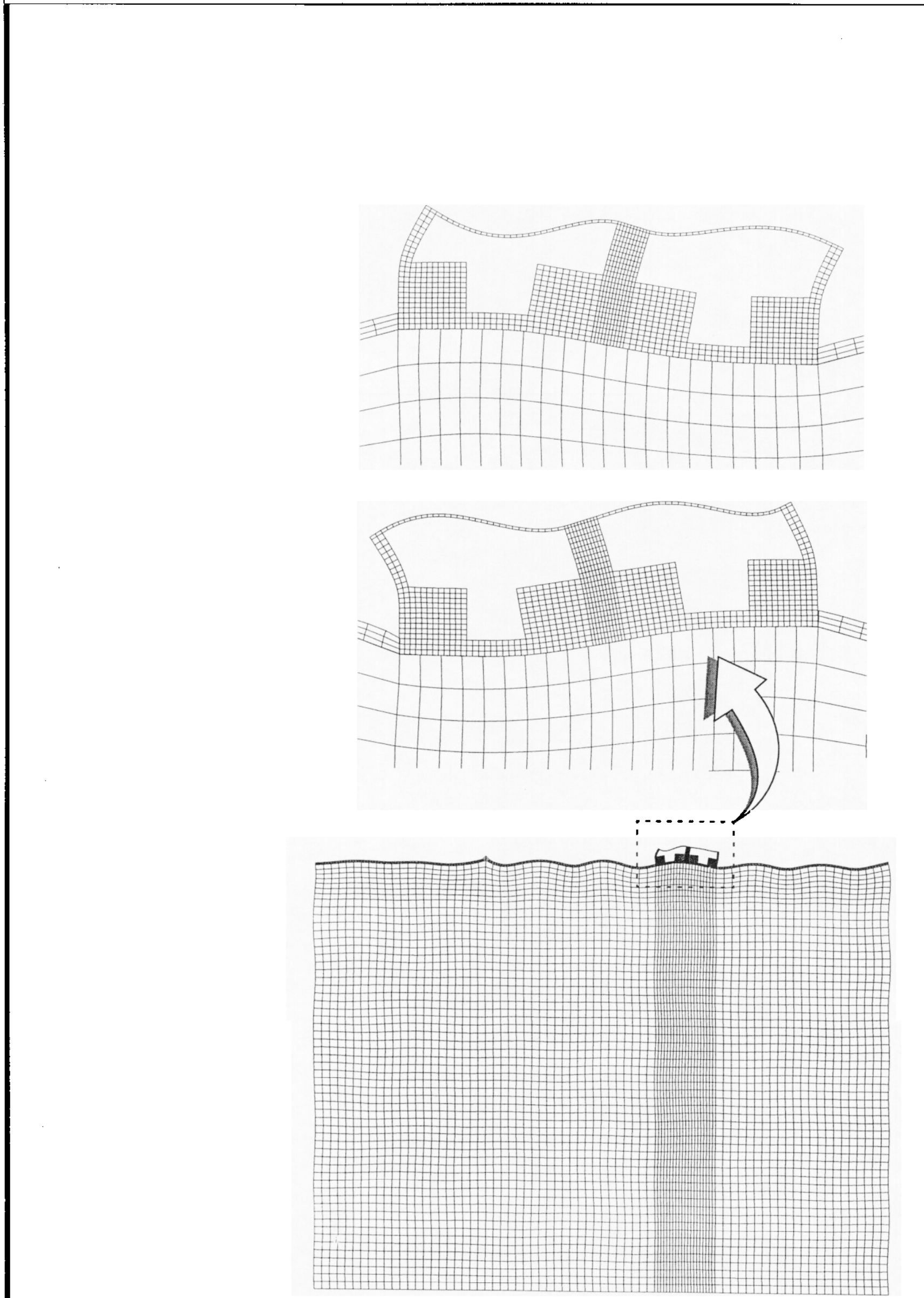

FIGURE 28. Deformed shape of the superstructure at selected time steps. 

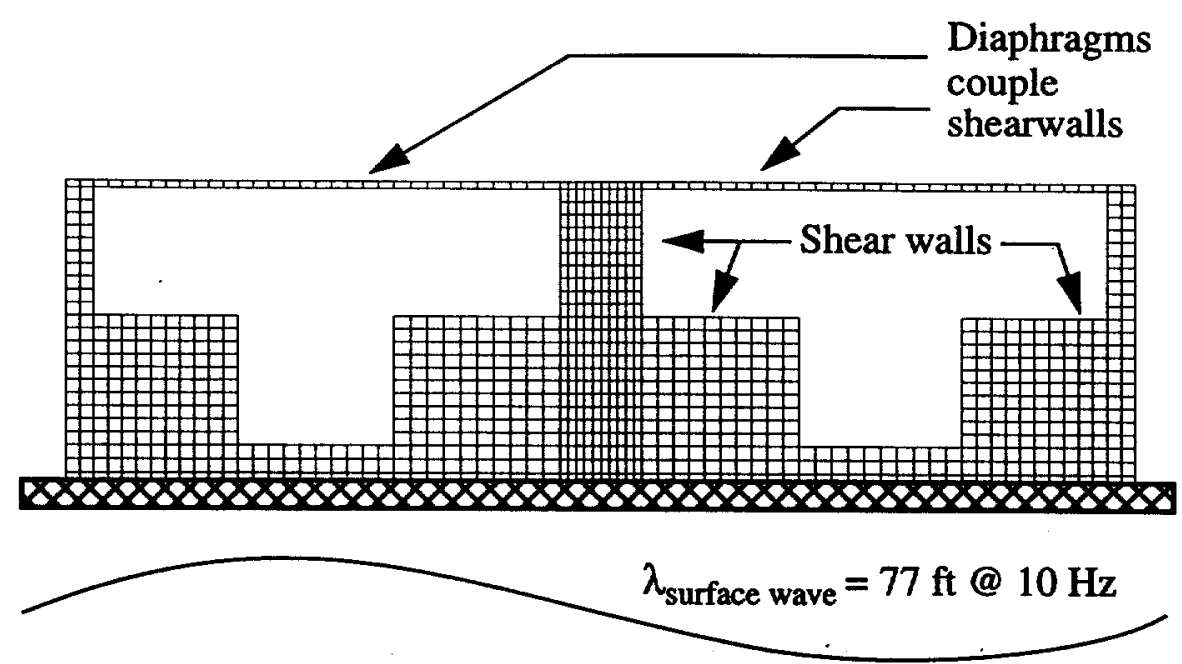

a)


FIGURE 29. Superstructure deformation for fixed base and coupled analyses. a) Fixed base analysis; b) coupled analysis. 


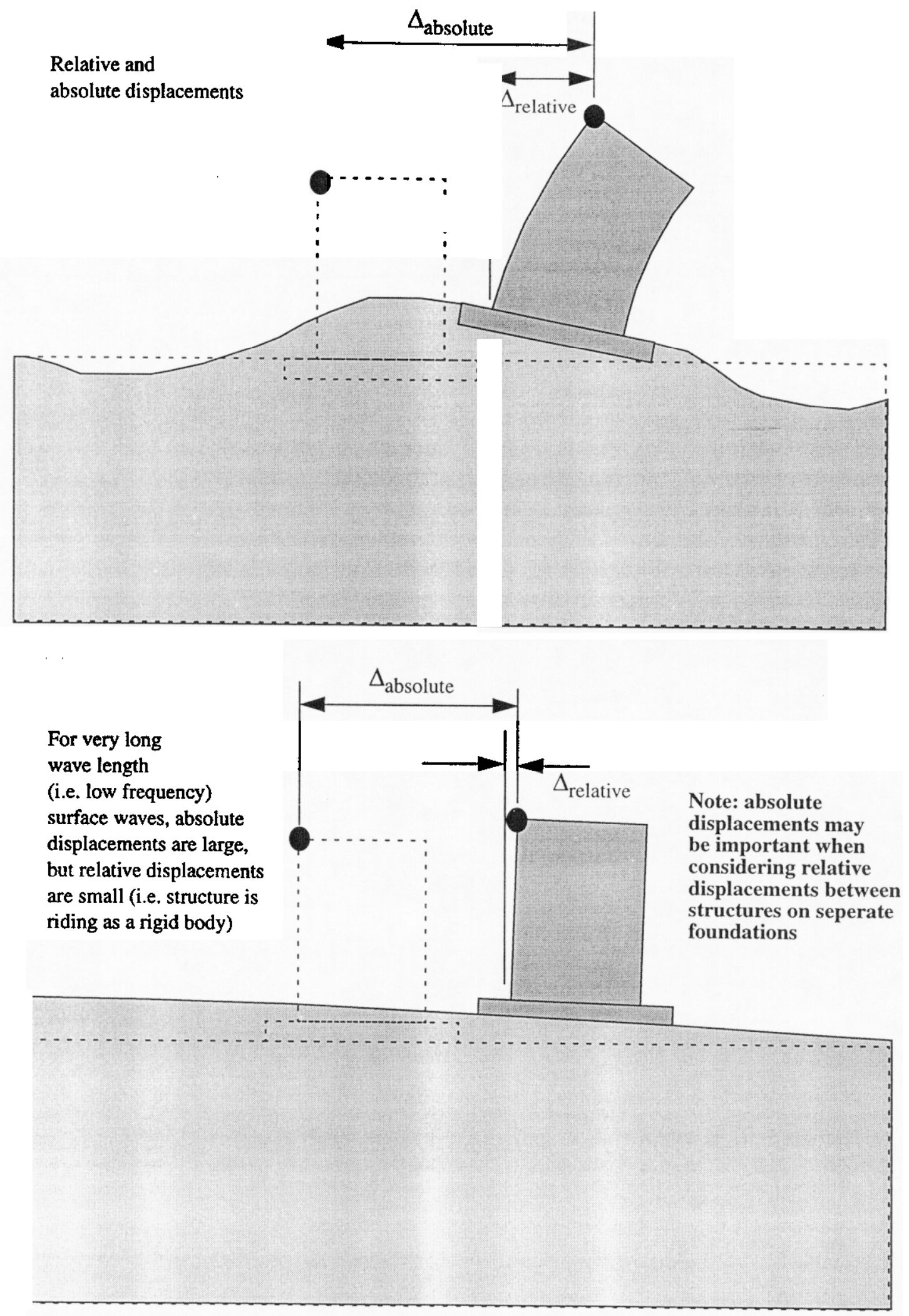

FIGURE 30. Relative and absolute displacements of the superstructure (displacement magnitudes grossly exaggerated). 
value of the relative displacement from the fully coupled case is approximately 1.4 times the RMS displacement from the decoupled analysis. The RMS displacement results are summarized in Table 1.

TABLE 1. RMS displacements from decoupled and coupled analyses.

\begin{tabular}{|c|c|c|}
\hline Analysis & $\begin{array}{c}\text { Relative } \\
\text { displacements at the } \\
\text { top of the shear wall }\end{array}$ & $\begin{array}{c}\text { Ratio of RMS } \\
\text { values (II/) }\end{array}$ \\
\hline I - Decoupled analysis & $2.49 \times 10^{-6}$ & \multirow{2}{*}{1.41} \\
\hline II - Coupled analysis & $3.52 \times 10^{-6}$ & \\
\hline
\end{tabular}

Inspection of rotations from the finite element models indicates an interesting trend. Whereas the relative displacements in the SSI case were consistantly larger that the relative displacements from the fixed base model, some of the local rotations in the fixed base case were larger than the corresponding rotations from the SSI problem. The nature of the structural deformation pattern for each of the cases provides some insight into why this is so. The deformed shape of the central shear wall is shown in Fig. 32 for the fixed base and SSI models respectively. The fixed base model has more curvature associated with the upper portion of the shear wall, and thus the rotations at the top of the wall are actually larger than the rotations from the SSI analyses. This is reflective of the fact that the shear wall is actually being subjected to larger shear forces in the fixed base case. The trend in the local rotations with wall height is shown in Fig. 32. 


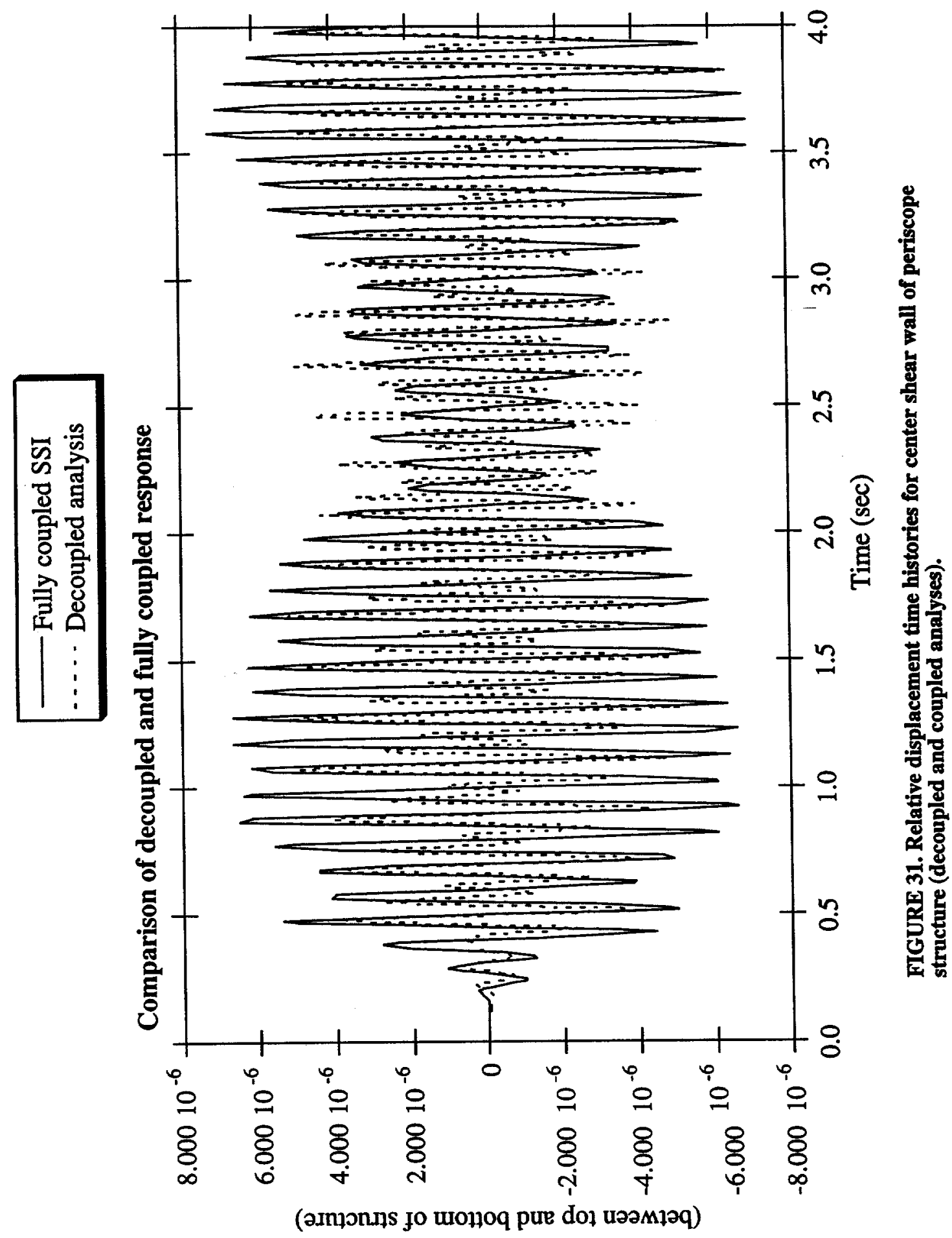

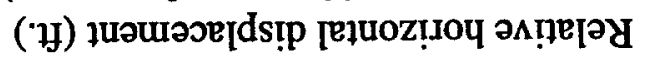



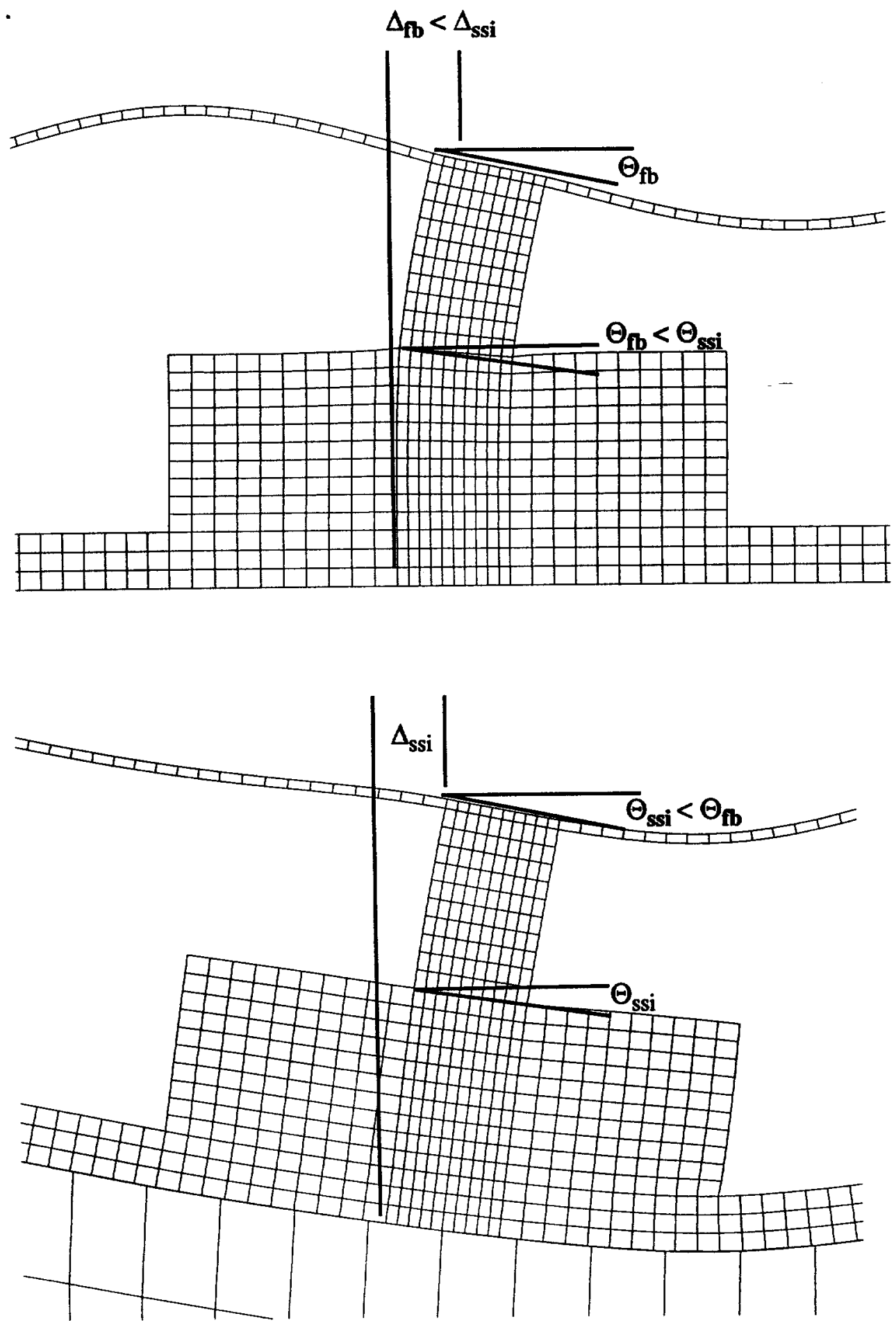

FIGURE 32. Displacements and rotations of fixed base and SSI models (larger displacement and rotation from either model is shown on both models, e.g. relative top-to-bottom displacement is larger for SSI model so that displacement is shown graphically on both models for comparative purposes). 


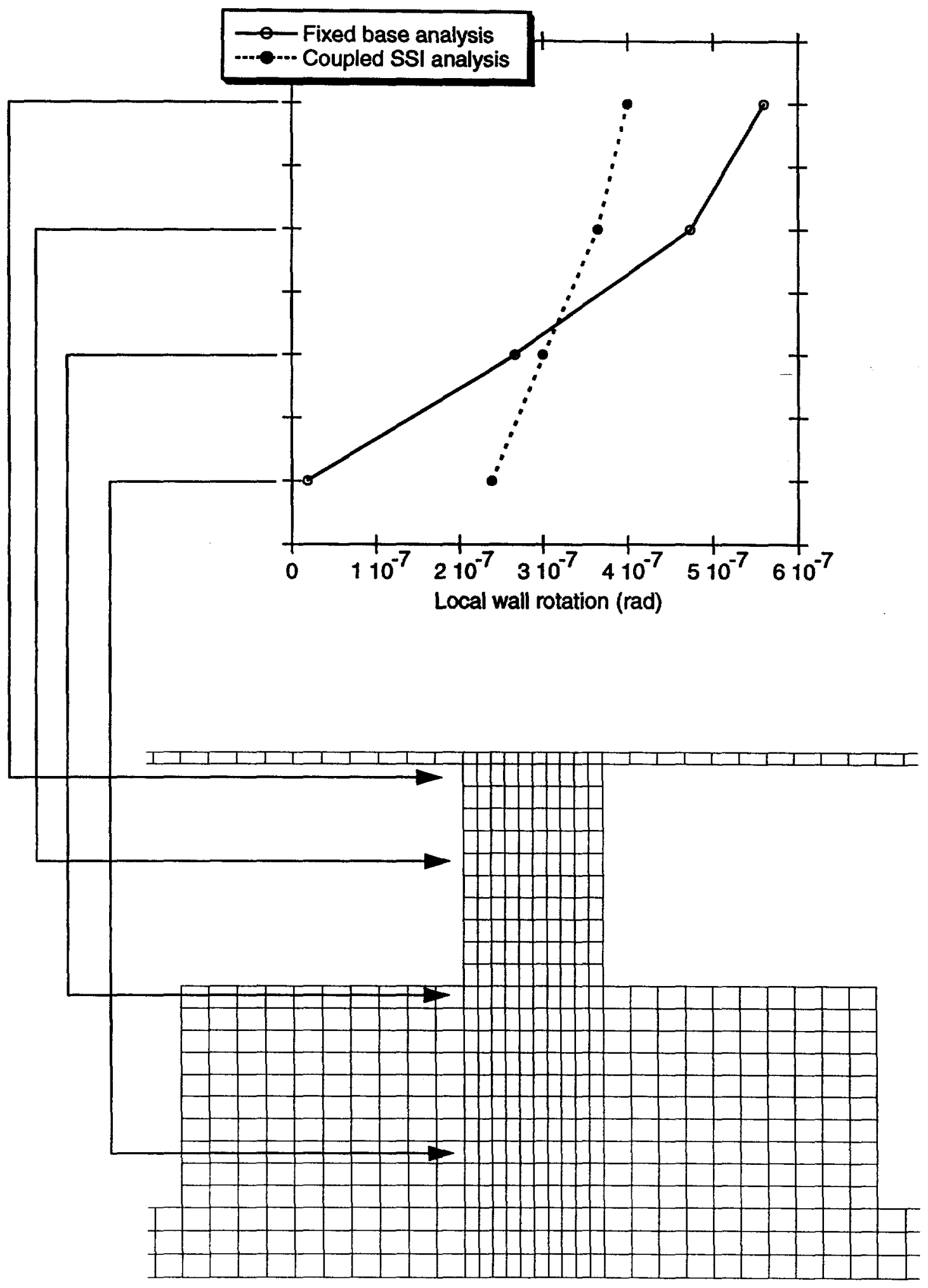

FIGURE 33. Local wall rotations as a function of wall height. 


\subsection{Summary and Conclusions}

The analyses contained herein have demonstrated that the interaction between the NIF special equipment structures and their soil/foundations is an important, first order factor in structural vibration stability considerations. Structural analysis based on classical fixedbased models with uniform input motion can significantly underestimate structural displacements and rotations.

It is not practical to perform a full SSI computation for each of the many structures under design, thus it will be necessary to utilize a limited number of full SSI analyses to develop simplified or empirical procedures for expedient modification of the fixed-based analysis results. One approach is to simply increase the fixed-base model results by a numeric factor to account for the effects of foundation flexibility and incoherent input motions. Based on the analyses performed in this study, a factor on the order of 1.4 to 1.5 appears to be reasonable and conservative for increasing the structure relative displacements. It is noted that the SSI analysis performed by Kleinfelder for the same structure found relative displacement increases on the order of 1.5 , thus there is significant consistancy between the time history analysis performed here and Kleinfelder's frequency domain calculations.

Because of the frequency range in which the stiff NIF special equipment structures will reside, it would be difficult to develop a reasonable approximate method for the SSI analyses. One option would be to attempt to place soil/foundation springs at the base of the structures to model the soil flexibility. However, as was indicated in this report the spatial variation of the ground motion, which leads to rotation input at the base of the structure, appears to be a higher effect than the inertial component of SSI and this effect would not be correctly represented with a simplified soil spring approach. The soil spring approach may have more validity for the target area where the massive vessel type structure will be more sensitive to the inertial component of SSI. 


\subsection{References}

1) Ambient Vibration and Seismic Velocity Measurements at the Lawrence Livermore National Laboratory Proposed National Ignition Facility Site, Hushmand and Associates, Report 9521-2101, 1996.

2) Personal communication between D. McCallen and P. Harben, Lawrence Livermore National Laboratory, 1996.

3) Miller, G.F. and Pursey, H., The Field and Radiation Impedence of Mechanical Radiators on the Free Surface of a Semi-Infinite Isotropic Solid, Proc. Royal Society, London, Vol. 223, pp 521-541.

4) Ewing, W.M., Jardetzky, W.S. and Press, F., Elastic Waves in Layered Media, McGrawHill, 1957.

5) McCallen, D.B. and Romstad, K.M., Nonlinear Model for Building-Soil Systems, Journal of Engineering Mechanics, ASCE, Vol. 120, No. 5, May 1994.

6) Seed, H.B., Lysmer, J. and Hwang, R., Soil-Structure Interaction Analysis for Seismic Response, Journal of the Geotechnical Engineering Division, ASCE, Vol. 101, No. GT5, May 1974.

7) Lysmer, J., and Kuhlemeyer, R.L., Finite Dynamic Model for Infinite Media, Journal of the Engineering Mechanics Division, ASCE, Vol. 95, No. 4, August 1968. 


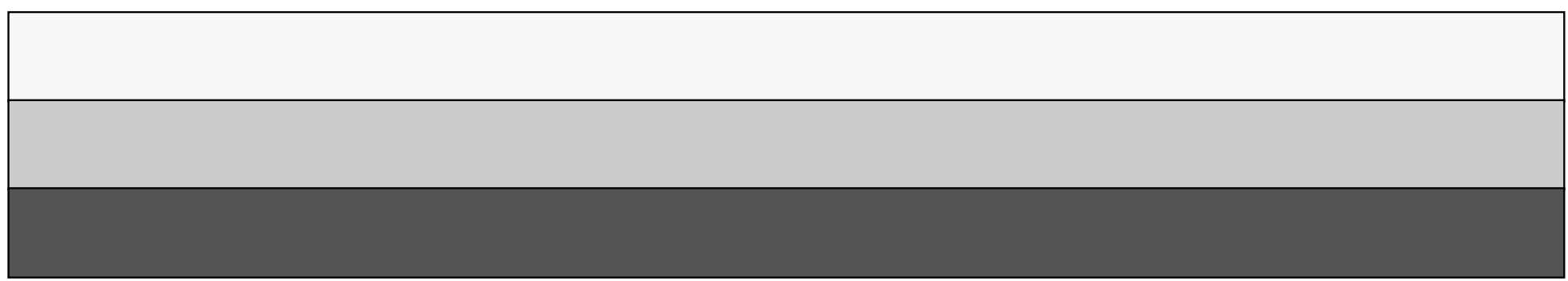

